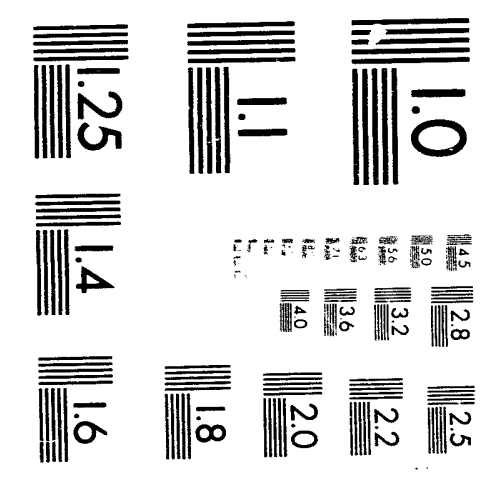



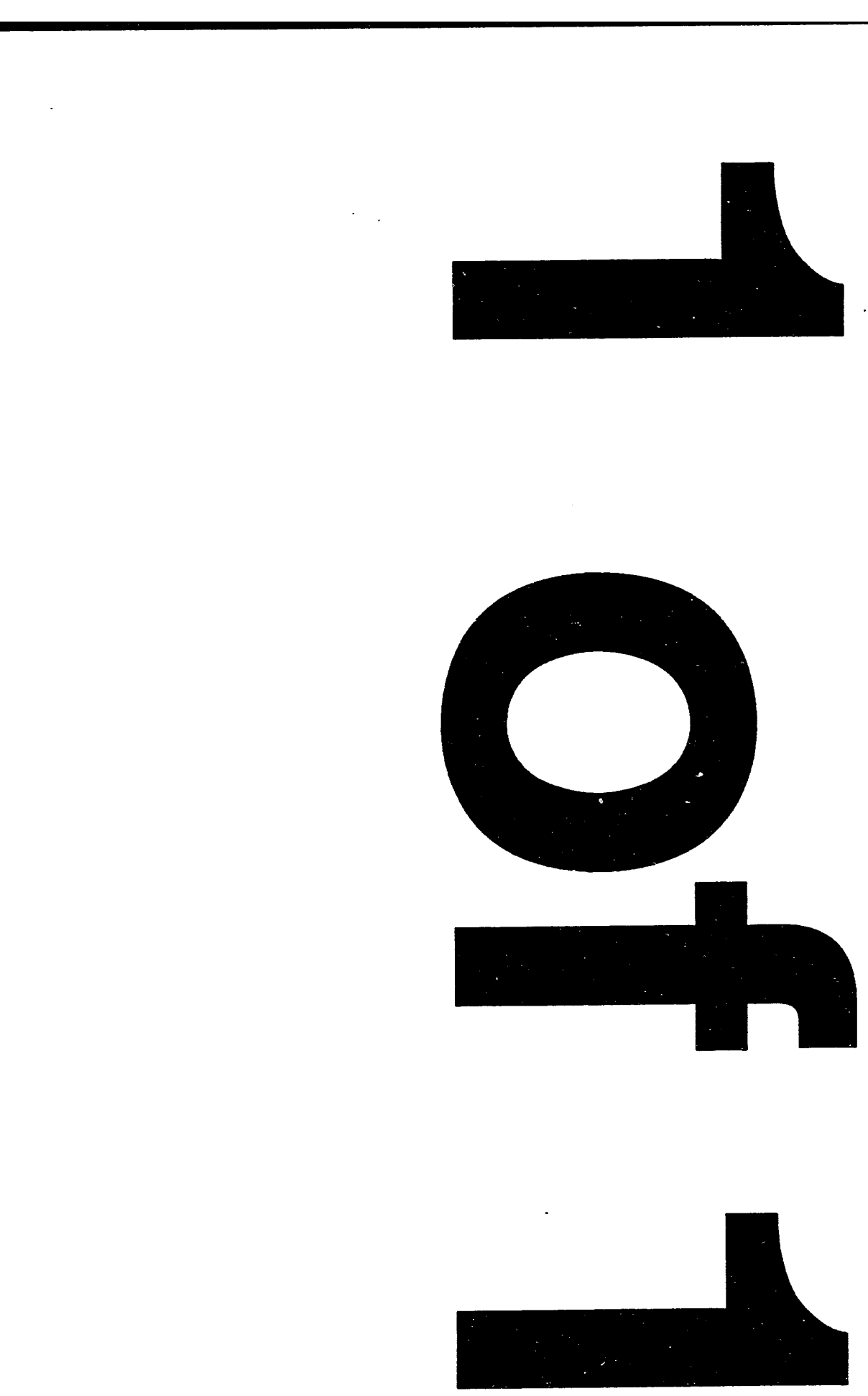
NUREG/CR-4469

PNL-5711

Vol. 16

R5

Nondestructive Examination

(NDE) Reliability for

Inservice Inspection of

Light Water Reactors

Semiannual Report

April 1992 - September 1992

Manuscript Completed: October 1993

Date Published: November 1993

Prepared by

S. R. Doctor, A. A. Diaz, J. R. Friley,

M. S. Greenwood, P. G. Heasler, R. J. Kurtz,

F. A. Simonen, J. C. Spanner, T. V. Vo

Pacific Northwest Laboratory

Richland, WA 99352

\section{Prepared for}

Division of Engineering

Office of Nuclear Regulatory Research

U.S. Nuclear Regulatory Commission

Washington, DC 20555-0001

NRC FIN B2289

\section{DISCLAIMER}

This report was prepared as an account of work sponsored by an agency of the United States Government. Neither the United States Government nor any agency thereof, nor any of their employees, makes any warranty, express or implied, or assumes any legal liability or responsibility for the accuracy, completeness, or usefulness of any information, upparatus, product, or process disclosed, or represents that its use would not infringe privately owned rights. Reference herein to any specific commercial product, process, or service by trade name, trademark, manufacturer, or otherwise does not necessarily constitute or imply its endorsement, recommendation, or favoring by the United States Government or any agency thereof. The views and opinions of authors expressed herein do not necessarily state or reflect those of the United States Government or any agency thereof.

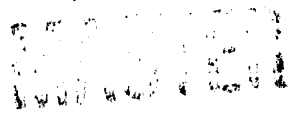




\begin{abstract}
The Evaluation and Improvement of NDE Reliability for Inservice Inspection of Light Water Reactors (NDE Reliability) Program at the Pacific Northwest Laboratory was established by the Nuclear Regulatory Commission to determine the reliability of surrent inservice inspection (ISI) techniques and to develop recommendations that will ensure a suitably high inspection reliability. The objectives of this program include determining the reliability of ISI performed on the primary systems of commercial light-water reactors (LWRs); using probabilistic fracture mechanics analysis to determine the impact of NDE unreliability on system safety;

and evaluating reliability improvements that can be achieved with improved and advanced technology. A final objective is to formulate recommended revisions to the Regulatory and ASME Code requirements, based on material properties, service conditions, and NDE uncertainties. The program scope is limited to ISI of the primary systems including the piping, vessel, and other components inspected in accordance with Section $\mathrm{XI}$ of the ASME Code. This is a progress report covering the programmatic work from April 1992 through September 1992.
\end{abstract}




\section{Contents}

Page

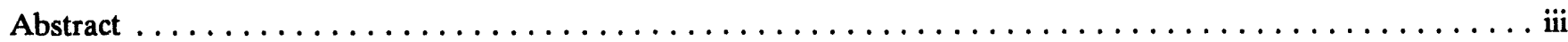

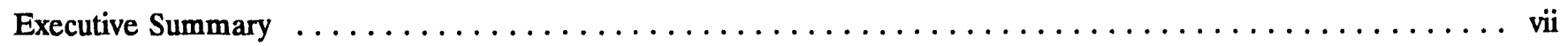

Previous Reports in Series $\ldots \ldots \ldots \ldots \ldots \ldots \ldots \ldots \ldots \ldots \ldots \ldots \ldots \ldots \ldots \ldots \ldots \ldots \ldots \ldots \ldots \ldots$

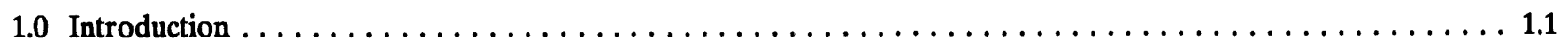

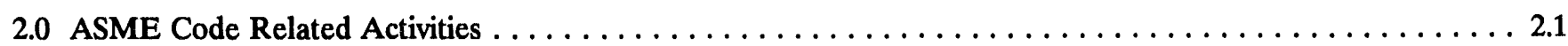

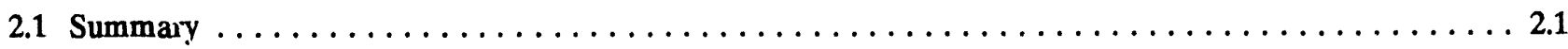

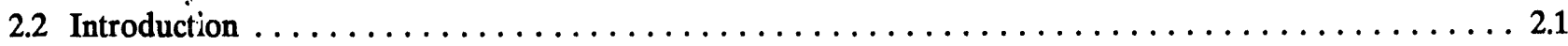

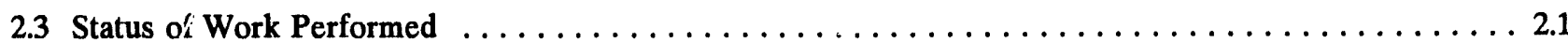

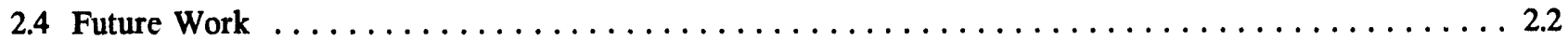

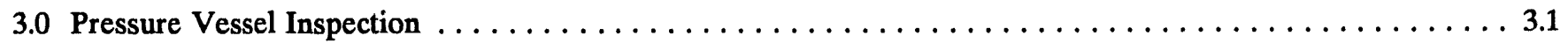

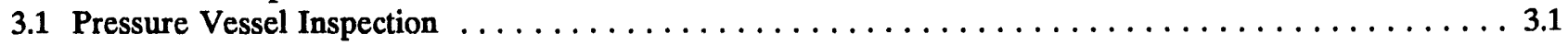

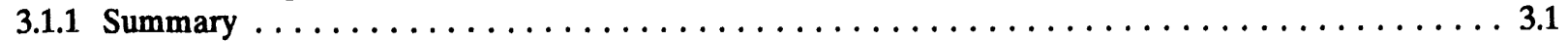

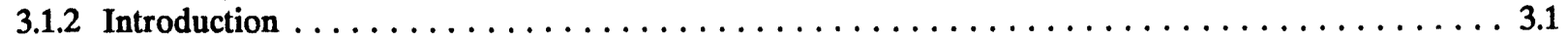

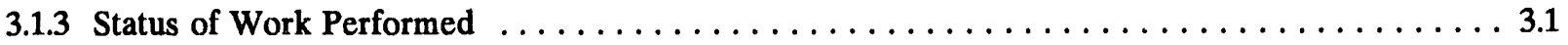

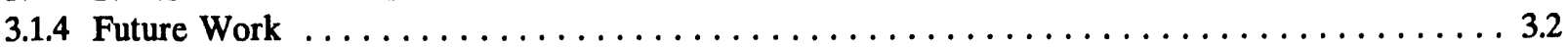

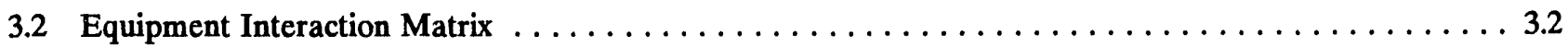

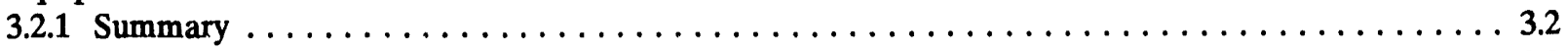

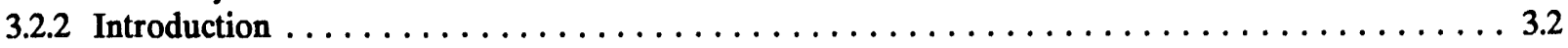

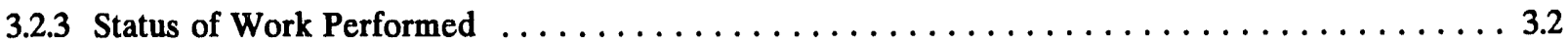

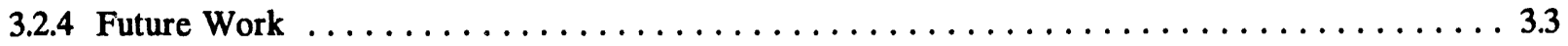

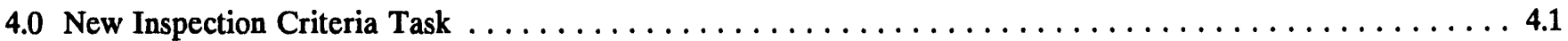

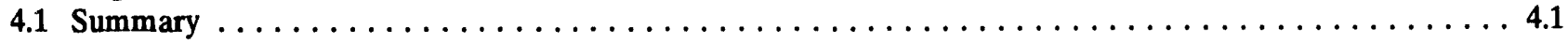

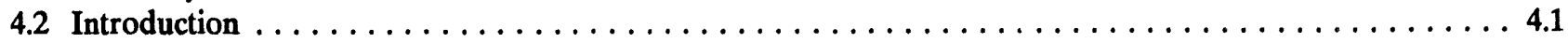

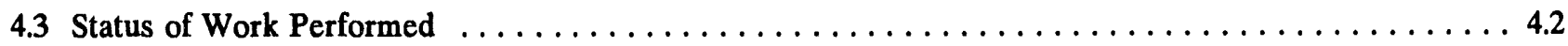

4.3.1 ASME Task Force on Risk-Based Inspection Guidelines $\ldots \ldots \ldots \ldots \ldots \ldots \ldots \ldots \ldots \ldots \ldots .2$

4.3.2 Plant Specific PRA Application to Surry-1 $\ldots \ldots \ldots \ldots \ldots \ldots \ldots \ldots \ldots \ldots \ldots \ldots \ldots \ldots$

4.3.3 Expert Judgement Elicitation for Rupture Probabilities $\ldots \ldots \ldots \ldots \ldots \ldots \ldots \ldots \ldots \ldots 4.3$

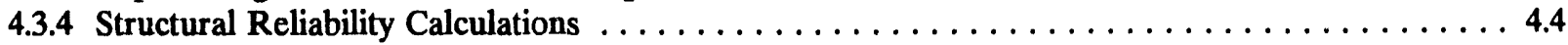

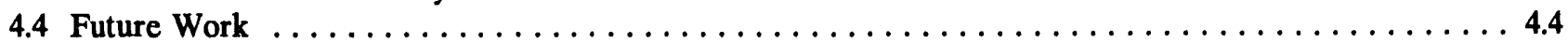

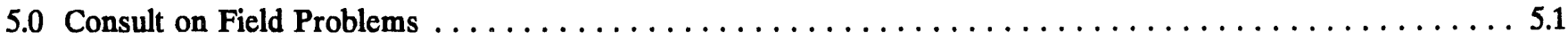

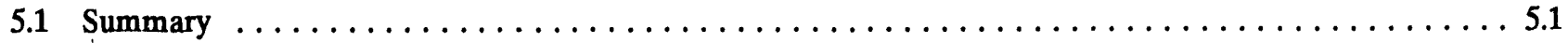

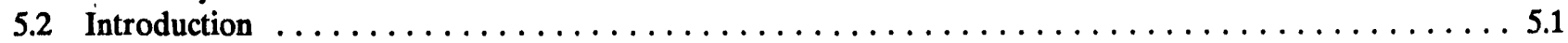

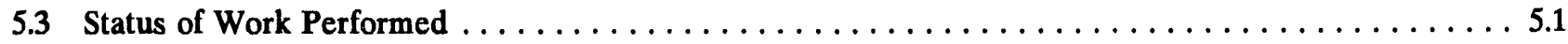

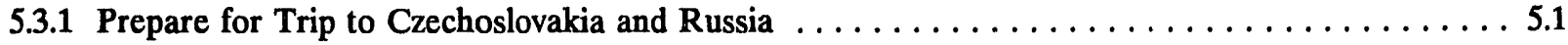

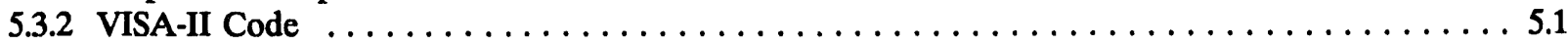

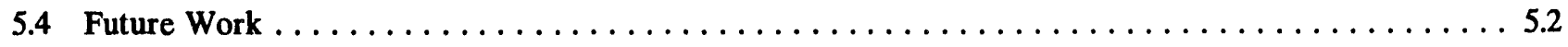




\section{Contents}

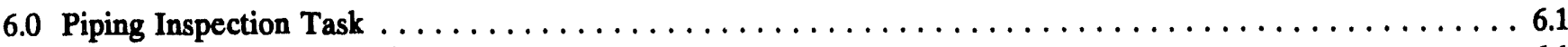

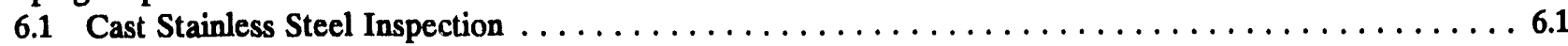

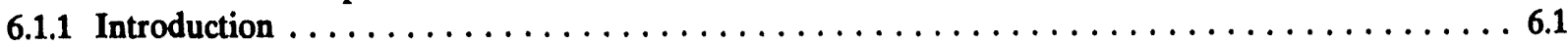

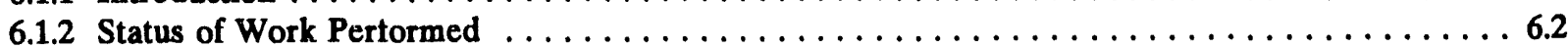

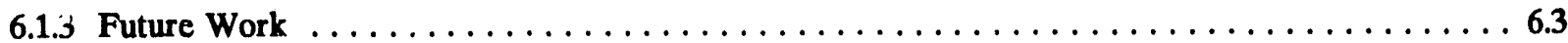

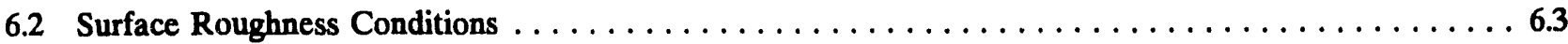

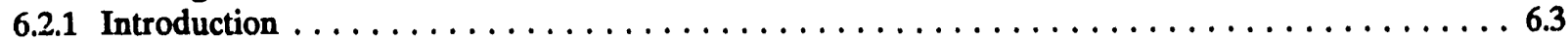

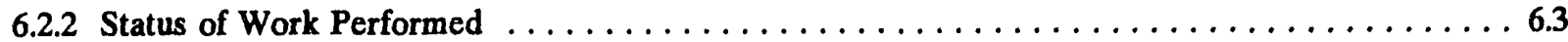

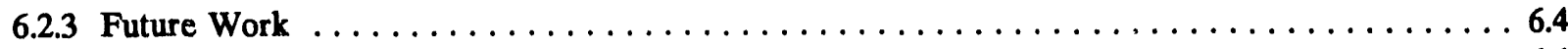

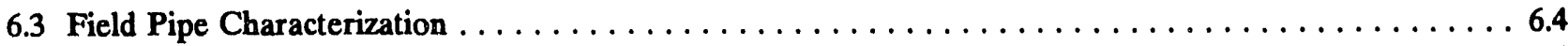

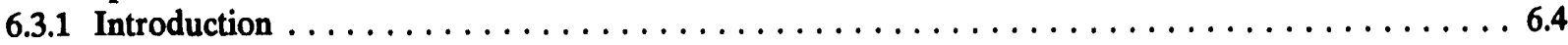

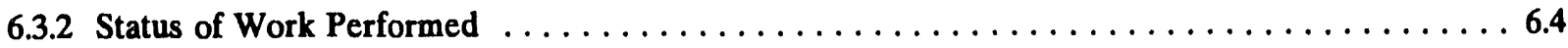

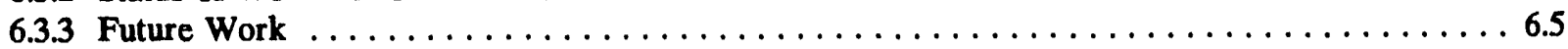

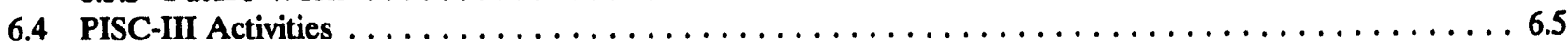

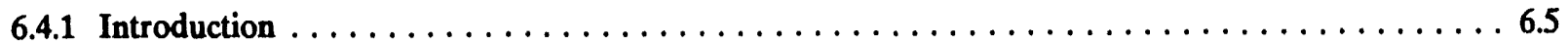

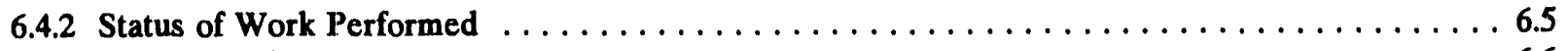

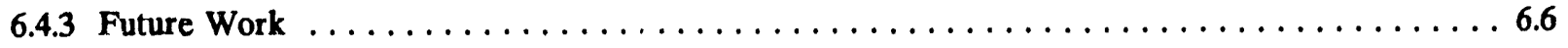

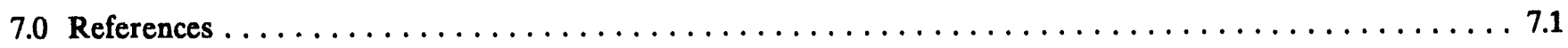

Appendix A: Ultrasonic Propagation through a Surface with a Step Discontinuity: Validation of a

Hybrid, Gauss-Hermite Ray Tracing Beam Model $\ldots \ldots \ldots \ldots \ldots \ldots \ldots \ldots \ldots \ldots$

\section{Tables}

5.1. Institutes and Personnel to be Contacted during Foreign Travel 


\section{Executive Summary ${ }^{1}$}

A multi-year program entitled the Evaluation and Improvement of NDE Reliability for Inservice Inspection of Light Water Reactors (NDE Reliability) was established at the Pacific Northwest Laboratory (PNL) to determine the reliability of current inservice inspection (ISI) techniques and to develop recommendations that would ensure a suitably high inspection reliability if fully implemented.

The objectives of this Nondestructive Examination (NDE) Reliability program for the Nuclear Regulatory Commission (NRC) include:

- Determine the reliability of ultrasonic ISI performed on the primary systems of commercial light-water reactors (LWRs).

- Use probabilistic fracture mechanics analysis to determine the impact of NDE unreliability on system safety and determine the level of inspection reliability required to ensure a suitably low failure probability.

- Evaluate the degree of reliability improvement that could be achieved using improved and advanced NDE techniques.

- Based on material properties, service conditions, and NDE uncertainties, formulate recommended revisions to Sections XI and V of the ASME Code and the Regulatory requirements needed to ensure suitably low failure probabilities.

The scope of the program is limited to the ISI of primary coolant systems, but the results and recommendations are also applicable to Class 2 piping systems.

The program consists of three basic tasks: a Piping task, a Pressure Vessel task, and a New Inspection Criteria task. The major highlights during this reporting period were:

\section{- $\quad$ ASME Code Activity}

Participation in ASME Section XI activities contin. ued toward achieving Code acceptance of NRC-

\footnotetext{
$1_{\text {RSR FIN. Budget No. B2289; RSR Contac: J. Murcan }}$
}

funded PNL research results to improve the reliability of nondestructive evaluation/inservice inspection (NDE/ISI). The most significant accomplishments included reviewing Appendices VII and VIII, and preparing recommendations for improving some noted shortcomings. Also, T-435 was approved by the Main Committee and the Board on Pressure Technology Codes and Standards.

\section{- Pressure Vessel Activities}

Re-analysis of PISC-II Data. The objective of this task is to determine the capability of U.S. ultrasonic inservice inspection of reactor pressure vessels. This objective is to be accomplished by utilizing data from PISC-II round robin trials, modelling, and limited experimental work to supplement areas not adequately addressed by modelling or round robin trials. All NRC comments on a draft report were addressed and a new draft was submitted for PNL internal review.

RPV Research. The objective of this subtask is to track work currently being performed under the PISC-III program; particularly work conducted under Actions 2 and 3. These actions provide useful information concerning the capability to inspect nozzles and dissimilar metal welds and will begin to address techniques for accurate flaw sizing as well as the reliability of vessel inspections. At this time, no results are available but these studies are expected to provide useful data bases and conclusions in the near future. Draft reports will be made available to the PISC-III Management Board in early 1993.

NDE Requirements for Aging Plants. The ASME Section XI rules and procedures for flaw evaluation were examined under this subtask. A draft report was prepared. During PNL internal review, it was discovered that additional input is needed prior to sending to the NRC for review.

Equipment Interaction Matrix. The objective of this work is to evaluate the effects of frequencydependent equipment interactions and determine equipment operating tolerance values for improving ultrasonic inspection reliability. A computer model is being used to calculate flaw transfer 
functions and frequency-dependent effects that occur due to the interaction between inspection equipment and worst-case flaws. Calculated values are also being compared with experimental measurements to determine if other measurementrelated effects, not programmed into the model, are significant enough for inclusion in the model.

During this reporting period, the computer code CURVE was validated for a cylinder of very large radius $(10 \mathrm{~m})$.

\section{- New Inspection Criteria}

Work continued on assessments of the adequacy of existing ASME Code requirements for ISI and on developing technical bases for improved ISI requirements that will contribute to high nuclear power plant component structural integrity. Development of a comprehensive probabilistic approach for improved inspection requirements moved forward. A major focus of this effort has continued to be participation in an ASME Research Task Force on Risk-Based Inspection Guidelines. During this reporting period, the ASME Task Force has completed a document specifically directed to light water reactor nuclear power plant components "Risk-Based Inspection Development of Guidelines - Volume 2 - Part 1 Light Water Reactor (LWR) Nuclear Power Plant Components," and publication as an ASME report is scheduled for December 1992.

Calculations have applied probabilistic risk assessment (PRA) to establish inspection priorities for pressure boundary systems and components. Plant-specific risk-based studies have been initiated for the Surry Unit 1 Nuclear Power Station, with the cooperation of Virginia Electric Power Company. During this reporting period, the ranking of components in the five remaining Surry-1 systems continued with site visits to compile detailed plant information and with analyses of the data from the expert elicitation workshop held in February 1992 to estimate component rupture probabilities for the five systems of interest.

Improved strategies for inspecting the piping and vessel components are being developed. Structural reliability calculations have continued with applica- tions of the pc-PRAISE code to predict leak and rupture probabilities for piping in the low f:essure injection system and to predict the benefits of alternative inspection scenarios on reducing these probabilities.

\section{- Consult on Field Problems}

The objective of this work is to provide a capid response to urgent and unexpected problems as they are identified by the Office of Nuclear Regulatory Research (RES). The most significant accomplishment was a trip to review and assess the NDE technologies in Czechoslovakia and Russia.

\section{- Piping Inspection Task}

This task is designed to address the NDT problems associated with piping used in light water reactors. The primary thrust of the work has been on wrought and cast stainless steel since these materials are harder to inspect than carbon steel. However, many of the subtasks' results also pertain to carbon steel. The current subtasks are: cast stainless steel inspection, surface roughness conditions, field pipe characterization, and PISCIII activities.

Cast Stainless Steel Inspection. The objective of this subtask is to evaluate the effectiveness and reliability of ultrasonic inspection techniques on LWR components containing cast stainless steel material. Far-side weld inspection is included in the scope of this work since the ultrasonic field passes through weld metal. Activities for this reporting period included an investigation of low frequency ultrasonic techniques inherently insensitive to macrostructural effects, a fracture mechanics evaluation aimed at estimating "critical" dimensions of circumferential cracks in centrifugally cast stainless steel (CCSS) primary pipe sections, and investigating the feasibility of implementing "adaptive ultrasonics" to the inspection of coarse-grained materials.

Surface Roughness. The objective of this subtask is to quantify and develop requirements to limit the adverse effects of surface conditions upon an ultrasonic inspection. Very good agreement has been found between the Center for Nondestructive 
Evaluation (CNDE) model and PNL laboratory measurements for steps from 0 to 60 mils, $0^{\circ}$ and $45^{\circ}$ longitudinal, and $45^{\circ}$ shear tests.

Field Pipe Characterization. The objective of this subtask is to provide pipe weld specimens that can be used for studies to evaluate the effectiveness and reliability of ultrasonic inservice inspection (UT/ISI) performed on BWR piping. The five safe-ends removed from the Monticello nuclear power station are no longer needed for any programmatic work, and processes to dispose of these samples are under review to meet the new requirements for disposal required by state and federal agencies.
PISC III. The objective of this subtask involves participation in the PISC-III program to ensure that the work addresses NDE reliability problems for materials and ISI practices on U.S. LWRs. This includes support for the co-leader of Action 4 on Austenitic Steel Tests (AST); providing a sector of the Hope Creek reactor pressure vessel containing two recirculation system inlet nozzles; coordination of the inspections to be conducted by U.S. teams on the various actions; and input to the studies on reliability and specimens for use in the parametric, capability, and reliability studies of the AST. During this reporting period, the most significant thing accomplished was finalizing the schedule for the USA teams for the cast-to-cast and the cast-to-wrought capabilities studies. 


\section{Previous Reports in Series}

Heasler, P. G., T. T. Taylor, and S. R. Doctor. 1993. Statistically Based Reevaluation of PISC-II Round Robin Test Data. NUREG/CR-5410, PNL-8577. Pacific Northwest Laboratory, Richland, Washington.

Doctor, S. R., A. A. Diaz, J. R. Friley, M. S. Good, M. S. Greenwood, P. G. Heasler, R. L. Hockey, R. J. Kurtz, F. A. Simonen, J. C. Spanner, T. T. Taylor, and T. V. Vo. 1993. Nondestructive Examination (NDE) Reliability for Inservice Inspection of Light Water Reactors. NUREG/CR-4469, PNL-5711, Vol. 15. Pacific Northwest Laboratory, Richland, Washington.

Doctor, S. R., A. A. Diaz, J. R. Friley, M. S. Good, M. S. Greenwood, P. G. Heasler, R. L. Hockey, R. J. Kurtz, F. A. Simonen, J. C. Spanner, T. T. Taylor, and T. V. Vo. 1992. Nondestructive Examination (NDE) Reliability for Inservice Inspection of Light Water Reactors. NUREG/CR-4469, PNL-5711, Vol. 14. Pacific Northwest Laboratory, Richland, Washington.

Green, E. R., S. R. Doctor, R. L. Hockey, and A. A. Diaz. 1992. Development of Equipment Parameter Tolerances for the Ultrasonic Inspection of Steel Components: Application to Components up to 3 Inches Thick. NUREG/CR-5817, Vol 1. Pacific Northwest Laboratory, Richland, Washington.

Doctor, S. R., M. S. Good, P. G. Heasler, R. L. Hockey, F. A. Simonen, J. C. Spanner, T. T. Taylor, and T. V. Vo. 1992. Nondestructive Examination (NDE) Reliability for Insenvice Inspection of Light Water Reactors. NUREG/CR-4469, PNL-5711, Vol. 13. Pacific Northwest Laboratory, Richlind, Washington.

Doctor, S. R., M. S. Gojd, P. G. Heasler, R. L. Hockey, F. A. Simonen, J. C. Spanner, T. T. Taylor, and T. V. Vo. 1992. Nondestructive Examination (NDE) Reliability for Inservice Inspection of Light Water Reactors. NUREG/CR-4469, PNL-5711, Vol. 12. Pacific Northwest Laboratory, Richland, Washington.

Doctor, S. R., M. S. Good, E. R. Green, P. G. Heasler, F. A. Simonen, J. C. Spanner, T. T. Taylor, and T. V. Vo. 1991. Nondestructive Examination (NDE) Reliability for Inservice Inspection of Light Water Reactors. NUREG/CR-4469, PNL-5711, Vol. 11. Pacific Northwest Laboratory, Richland, Washington.
Heasler, P. G., T. T. Taylor, J. C. Spanner, S. R. Doctor, and J. D. Deffenbaugh. 1990. Ultrasonic Inspection Reliability for Intergranular Stress Corrosion Cracks: $A$ Round Robin Study of the Effects of Personnel, Procedures, Equipment and Crack Characteristics. NUREG/CR-4908. Pacific Northwest Laboratory, Richland, Washington.

Spanner, J. C., S. R. Doctor, T. T. Taylor/PNL and J. Muscara/NRC. 1990. Qualification Process for Ultrasonic Testing in Nuclear Inservice Inspection Applications. NUREG/CR-4882, PNL-6179. Pacific Northwest Laboratory, Richland, Washington.

Doctor, S. R., J. D. Deffenbaugh, M. S. Good, E. R. Green, P. G. Heasler, F. A. Simonen, J. C. Spanner, T. T. Taylor, and T. V. Vo. 1990. Nondestructive Examination (NDE) Reliability for Inservice Inspection of Light Water Reactors. NUREG/CR-4469, PNL-5711, Vol. 10. Pacific Northwest Laboratory, Richland, Washington.

Doctor, S. R., J. D. Deffenbaugh, M. S. Good, E. R. Green, P. G. Heasler, F. A. Simonen, J. C. Spanner, and T. T. Taylor. 1989. Nondestructive Examination (NDE) Reliability for Inservice Inspection of Light Water Reactors. NUREG/CR-4469, PNL-5711, Vol. 9. Pacific Northwest Laboratory, Richland, Washington.

Doctor, S. R., J. D. Deffenbaugh, M. S. Good, E. R. Green, P. G. Heasler, F. A. Simonen, J. C. Spanner, and T. T. Taylor. 1989. Nondestructive Examination (NDE) Reliability for Insenvice Inspection of Light Water Reactors. NUREG/CR-4469, PNL-5711, Vol. 8. Pacific Northwest Laboratory, Richland, Washington.

Doctor, S. R., J. D. Deffenbaugh, M. S. Good, E. R. Green, P. G. Heasler, F. A. Simonen, J. C. Spanner, and T. T. Taylor. 1988. Nondestructive Examination (NDE) Reliability for Inservice Inspection of Light Water Reactors. NUREG/CR-4469, PNL-5711, Vol. 7. Pacific Northwest Laboratory, Rich'and, Washington.

Doctor, S. R., J. D. Deffenbaugh, M. S. Good, E. R. Green, P. G. Heasler, G. A. Mart, F. A. Simonen, J. C. Spanner, T. T. Taylor, and L. G. Van Fleet. 1987. Nondestructive Examination (NDE) Reliability for Inservice Inspection of Light Water Reactors. NUREG/CR- 
Previous Reports

4469, PNL-5711, Vol. 6. Pacific Northwest Laboratory, Richland, Washington.

Doctor, S. R., D. J. Bates, J. D. Deffenbaugh, M. S. Good, P. G. Heasler, G. A. Mart, F. A. Simonen, J. C. Spanner, T. T. Taylor, and L. G. Van Fleet. 1987. Nondestructive Examination (NDE) Reliability for Inservice Inspection of Light Water Reactors. NUREG/CR4469, PNL-5711, Vol. 5. Pacific Northwest Laboratory, Richland, Washington.

Doctor, S. R., D. J. Bates, J. D. Deffenbaugh, M. S. Good, P. G. Heasler, G. A. Mart, F. A. Simonen, J. C. Spanner, A. S. Tabatabai, T. T. Taylor, and L. G. Van Fleet. 1987. Nondestructive Examination (NDE) Reliability for Inservice Inspection of Light Water Reactors. NUREG/CR-4469, PNL-5711, Vol. 4. Pacific Northwest Laboratory, Richland, Washington.

Collins, H. D. and R. P. Gribble. 1986. Siamese Imaging Technique for Quasi-Vertical Type (QVT) Defects in Nuclear Reactor Piping. NUREG/CR-4472, PNL-5717. Pacific Northwest Laboratory, Richland, Washington.

Doctor, S. R., D. J. Bates, R. L. Bickford, L. A. Charlot, J. D. Deffenbaugh, M. S. Good, P. G. Heasler, G. A. Mart, F. A. Simonen, J. C. Spanner, A. S. Tabatabai, T. T. Taylor, and L. G. Van Fleet. 1986. Nondestructive Examination (NDE) Reliability for Inservice Inspection of Light Water Reactors. NUREG/CR4469, PNL-5711, Vol. 3. Pacific Northwest Laboratory, Richland, Washington.

Doctor, S. R., D. J. Bates, L. A. Charlot, M. S. Good, H. R. Hartzog, P. G. Heasler, G. A. Mart, F. A. Simonen, J. C. Spanner, A. S. Tabatabai, and T. T. Taylor. 1986. Evaluation and Improvement of NDE Reliability for Inservice Inspection of Light Water Reactors. NUREG/CR-4469, PNL-5711, Vol. 2. Pacific Northwest Laboratory, Richland, Washington.

Doctor, S. R., D. J. Bates, L. A. Charlot, H. D. Collins, M. S. Good, H. R. Hartzog, P. G. Heasler, G. A. Mart, F. A. Simonen, J. C. Spanner, and T. T. Taylor. 1986. Integration of Nondestructive Examination (NDE) Reliability and Fracture Mechanics, Semi-Annual Report, April 1984 - September 1984. NUREG/CR-4469, PNL5711, Vol. 1. Pacific Northwest Laboratory, Richland, Washington.
Good, M. S. and L. G. Van Fleet. 1986. Status of Activities for Inspecting Weld Overlaid Pipe Joints. NUREG/CR-4484, PNL-5729. Pacific Northwest Laboratory, Richland, Washington.

Heasler, P. G., D. J. Bates, T. T. Taylor, and S. R. Doctor. 1986. Performance Demonstration Tests for Detection of Intengranular Stress Corrosion Cracking. NUREG/CR-4464, PNL-5705, Pacific Northwest Laboratory, Richland, Washington.

Simonen, F. A. 1984. The Impact of Nondestructive Examination Unreliability on Pressure Vessel Fracture Predictions. NUREG/CR-3743, PNL-5062. Pacific Northwest Laboratory, Richland, Washington.

Simonen, F. A. and H. H. Woo. 1984. Analyses of the Impact of Inservice Inspection Using Piping Reliability Model. NUREG/CR-3753, PNL-5070. Pacific Northwest Laboratory, Richland, Washington.

Taylor, T. T. 1984. An Evaluation of Manual Ultrasonic Inspection of Cast Stainless Steel Piping.

NUREG/CR-3753, PNL-5070. Pacific Northwest Laboratory, Richland, Washington.

Bush, S. H. 1983. Reliability of Nondestructive Examination, Volumes I, II, and III. NUREG/CR-3110-1, -2, and -3; PNL-4584. Pacific Northwest Laboratory, Richland, Washington.

Simonen, F. A. and C. W. Goodrich. 1983. Parametric Calculations of Fatigue Crack Growth in Piping. NUREG/CR-3059, PNL-4537. Pacific Northwest Laboratory, Richland, Washington.

Simonen, F. A., M. E. Mayfield, T. P. Forte, and D. Jones. 1983. Crack Growth Evaluation for Small Cracks in Reactor-Coolant Piping. NUREG/CR-3176, PNL-4642. Pacific Northwest Laboratory, Richland, Washington.

Taylor, T. T., S. L. Crawford, S. R. Doctor, and G. J. Posakony. 1983. Detection of Small-Sized Near-Surface Under-Clad Cracks for Reactor Pressure Vessels. NUREG/CR-2878, PNL-4373. Pacific Northwest Laboratory, Richland, Washington. 
Busse, L. J., F. L. Becker, R. E. Bowey, S. R. Doctor, R. P. Gribble, and G. J. Posakony. 1982. Characterization Methods for Ultrasoric Test Systems.

NUREG/CR-2264, PNL-4215. Pacific Northwest Laboratory, Richland, Washington.

Morris, C. J. and F. L. Becker. 1982. State-of-Practice Review of Ultrasonic In-service Inspection of Class I System Piping in Commercial Nuclear Power Plants.

NUREG/CR-2468, PNL-4026. Pacific Northwest Laboratory, Richland, Washington.
Becker, F. L., S. R. Doctor, P. G. Heasler, C. J. Morris, S. G. Pitman, G. P. Selby, and F. A. Simonen. 1931. Integration of NDE Reliability and Fracture Mechanics, Phase I Report. NUREG/CR-1696-1, PNL-3469. Pacific Northwest Laboratory, Richland, Washington.

Taylor, T. T. and G. P. Selby. 1981. Evaluation of ASME Section XI Reference Level Sensitivity for Initiation of Ultrasonic Inspection Examination.

NUREG/CR-1957, PNL-3692. Pacific Northwest Laboratory, Richland, Washington. 


\subsection{Introduction}

The Evaluation and Improvement of NDE R.eliability for Inservice Inspection of Light Water Reactors (NDE Reliability) Program at Pacific Northwest Laburatory (PNL) was established to determine the reliability of current inservice inspection (ISI) techniques and to develop recommendations that would ensure a suitably high inspection reliability if fully implemented. The objectives of this program for the Nuclear Regulatory Commission (NRC) are:

- Determine the reliability of ultrasonic ISI performed on commercial light-water reactor (LWR) primary systems.

- Use probabilistic fracture mechanics analysis to determine the impact of NDE unreliability on system safety and determine the level of inspection reliability required to insure a suitably low failure probability.

- Evaluate the degree of reliability improvement that could be achieved using improved and advanced NDE techniques.
- Based on material properties, service conditions, and NDE uncertainties, formulate recommended revisions to Section XI of the Regulatory and ASME Code requirements needed to ensure suitably low failure probabilities.

The scope of this program has been focused on the ISI of the primary coolant systems; however, the program has been expanded to include all components where structural failure can contribute significantly to plant risk.

This report is divided into the following sections.

- ASME Code Related Activities

- Pressure Vessel Inspection

- New Inspection Criteria

- Consult on Field Problems

- Piping Task Activities 


\subsection{ASME Code Related Activities}

\subsection{Summary}

Participation in ASME Section XI and V activities continued toward achieving Code acceptance of NRCfunded PNL rescarch results to improve the reliability of nondestructive examination/inservice inspection (NDE/ISI). Minutes of the ASME Section XI Subgroup on Nondestructive Examination (SGNDE) meetings held Fcbruary 1992 in Atlanta, GA and May 1992 in San Antonio, TX were prepared, finalized, and distributed. Minutes for the SGNDE meeting held August 1992 in Chicago, IL were drafted and assembled with attachments. Mectings of the Section V Subgroups on Ultrasonic Testing (SGUT) and on Acoustic Emission (SGAE) were attended during ASNiE Section V meetings held in May 1992 in San Antonio, TX.

The PNL-proposed T-435 document on "Computerized Imaging Techniques" was approved by the ASME Main Committec (M.C.) and the ASME Board on Pressure Technology Codes and Standards.

A liaison report was presented during the September 1992 Scction V meetings on SC-XI SGNDE activities, and a brief report was given on the on-going PISC-III program human reliability work.

\subsection{Introduction}

The objective of this task is to develop and/or evaluate new criteria and requirements for qualifying ultrasonic testing/inservice inspection (UT/ISI) and other NDE/ISI systems. The ultimate goal is for these criteria and requirements to be incorporated into Sections $\mathrm{XI}$ and $\mathrm{V}$ (SC-XI and SC-V) of the ASME Boiler and Pressure Vessel Code (ASME Code).

To implement this goal, PNL staff members are active participants in Section XI and Section V ASME Code committee activities. PNL staff members serve as secretary of the SC-XI SGNDE, chair a SC-V task group to devclop acoustic emission requirements, and serve as members of the SC-XI Working Group on Surface Examination and Personnel Qualification (WGS) and the SC-XI Working Group on Volumetric Examination and Procedure Qualification (WG-V). In addition, PNL personnel serve as members of the SC-V Subgroup on Ultrasonic Testing (SGUT) and the SC-V
Subgroup on Acoustic Emission (SGAE). Administrative assistance is also provided in support of related efforts to achieve ASME Code acceptance of new personnel qualification (PQ) and performance demonstration (PD) requirements for eddy current equipment operators and data analysts, adoption of American National Standard Institute (ANSI) requirements for personnel qualification, and the SC-V activity to develop requirements and criteria for computerized UT imaging techniques.

\subsection{Status of Work Performed}

Proactive participation of PNL personnel in ASME Code activities continued toward achieving Code acceptance of NRC-funded PNL research results to improve the reliability of NDE/ISI. During this reporting period, meetings of the ASME Section XI Subcommittes (including relevant Subgroup and Working Group rieetings) were attended May 4-7, 1992 in San Antonio, TX (joint Code Committee meeting), and August 10-13, 1992 in Chicago, IL. Agendas and minutes of the SGNDE meetings held in conjunction with the Section XI Subcommittee meetings were prepared and distributed. Trip reports summarizing key activities that occurred during the ASME Code meetings were prepared for submittal to the NRC program monitor.

Viewgraphs and supporting materials were assembled in preparation for the annual NRC program review conducted by the project monitor. This program review was held in conjunction with the NRC's NDE Technical Advisory Group (TAG) meeting at PNL during the week of April 27, 1992. Several presentations on various NRC-funded tasks and supporting activities were made and discussed during the TAG meeting and the NRC program review.

During the SGNDE meeting, it was reported that a new SC-XI task group has been formed to work with the ASME Risk-Based Inspection Committee; presumably the first step toward adoption of some of this special committee's recommendations. It was reported that approval of the new Subsection IWH (i.e., pipe thinning due to erosion/corrosion) has been placed in a "hold" status pending work proceeding on a Code Case to address this issue. It was also reported that EPRI NDE Center personnel are drafting a proposal to limit 
UT of vesscls to a portion of the inner and outer zones of the RPV wall, and this draft will be forwarded to the Subgroup on Water Cooled Systems (SGWCS) and the Task Group on Optimization for consideration.

During the May meeting, the M.C. approved SC-XI adoption of ASNT's new PQ standard (ANSI/ASNT CP-189). Unfortunately, this approval included an exemption that deleted a prerequisite requirement that Level III personnel possess a valid ASNT Certificate. The status of proposed changes to Supplements 2 and 3, and proposed new Supplements 9, 10, 11, and 12 to Appendix VIII was highlighted. The WG-V approved this submittal in May and intends to request SGNDE approval during the August meeting.

The Appendix IV rules for eddy current ISI of steam generator (S.G.) tubes have been incorporated into Article 8 of SC-V; hence, Appendix IV will be deleted from SC-XI except for the personnel qualification requirements. Revised PQ requirements for ISI of S.G. tubes were approved for publication in Section XI.

Selected Section V Subgroup and Subcommittee meetings were also attended during the May meeting, which was a joint meeting of all of the ASME Boiler and Pressure Vessel Code committees. Final approval of the PNL-proposed T-435 requirements for computerized UT imaging systems was achieved. This document has now reccived both M.C. approval and letter ballot approval by the ASME Board on Pressure Vessel Technology (BPVT), and these requirements will be published in the 1992 Edition of Section V.

A draft letter documenting PNL's review of Appendix VII, including recommended revisions, was prepared and submitted to the NRC program monitor for review and endorsement prior to transmittal to the SGNDE Chairman for action.
An in-depth review of Appendix VIII (including the existing and proposed new appendices) was conducted and a letter to the authors at the EPRI NDE Center was drafted and circulated for internal PNL review in early June. This letter was finalized and distributed in July following informal endorsement by the NRC project monitor. This letter was submitted to the SGNDE Chairman with copy coverage to the document authors at the EPRI NDE Center, the WG-V Chairman, and the Performance Demonstration Initiative (PDI) Chairman.

During the August 1992 SC-XI meeting in Chicago, IL, the proposed revisions to Appendix VIII Supplements 2 and 3 and new Supplements 10, 11, and 12 were approved by the SGNDE and SC-XI. Supplemeat 9 on centrifugally cast stainless steel (CCSS) was not approved and was placed in a hold status pending additional work by members of the Task Group on UT.

A letter documenting PNL's review of Appendix VII, including recommended revisions, was submitted to the SGNDE Chairman and the cognizant Working Group Chairman (WG-S).

\subsection{Future Work}

Minutes for the ASME Section XI SGNDE meeting held August 1992 in Chicago, IL will be finalized for distribution to the approximately 65 recipients. Administrative support will continue for the various ASME Code activities of interest to the NRC and PNL, and development of Article 13 on "Continuous AE Monitoring" will continue.

Agendas and minutes will be prepared 4-6 weeks prior to each Section XI meeting. Future Section XI meetings will be held December 1992 in Louisville, KY (joint ASME PV Code Committee meeting); January 1993 in Albuquerque, NM; May 1993 in San Diego, CA (in conjunction with the National Board meeting); August 1993 in Greensboro, NC; and November 1993 in Atlanta, GA (joint ASME Code Committee meeting). 


\subsection{Pressure Vessel Inspection}

\subsection{Pressure Vessel Inspection}

\subsubsection{Summary}

The objective of this task is to determine the capability of U.S. ultrasonic inservice inspection of reactor pressure vessels. This objective is to be accomplished by utilizing data from PISC-II round robin trials, modelling, and limited experimental work to supplement areas not adequately addressed by modelling or round robin trials. Additional comments have been received from the draft report on the re-analysis of the PISC-II data, and these comments are being addressed. A final version of this report addressing NRC comments was completed and submitted for internal PNL review.

\subsubsection{Introduction}

The pressure vessel inspection task is divided into three subtasks:

- PISC II Re-analysis - The effort in this task is a re-analysis of data gathered during the PISC-II round robin trials using statistically based techniques. Ultrasonic inspection data was gathered on four heavy section steel components which included two plates and two nozzles configurations. A total of $\mathbf{4 5}$ teams from the Common Market, Japan, and the United States participated in the round robins.

- RPV Research - The focus of this activity is to track the work being performed under the PISC III program. This is intended to ensure that the PISC III work of the Action 2 on Full Scale Vessel Tests (FSV) and the Action 3 on Nozzles and Dissimilar Metal Welds provides useful information for conditions and practices in the USA. This subtask will also track the PISC III work and relay to the NRC points of interest and concern that may arise from the analysis of the ncwly created and evolving data base. During this reporting period the work focused on the review of preliminary PISC-III data. Draft reports are expected to be available to the PISC-III Management Board in early 1993.

- NDE Requirements for Aging Plants - The objective of this subtask is to determine if special inser- vice inspection (ISI) requirements are needed to address aging in nuclear power plants. Efforts have focussed on reviewing the technical bases for existing reactor pressure vessel (RPV) flaw acceptance criteria. The RPV was selected for initial study since it was judged to be the most important component unlikely to be replaced and is the component most susceptible to radiation damage.

\subsubsection{Status of Work Performed}

A summary of the work performed for each subtask is provided below.

\subsubsection{PISC II Re-analysis}

A summary of the analysis was provided in semi-annual report NUREG/CR-4469, Vol. 11. The work performed during this time period, completed addressing all of the NRC comments on the draft report. This completed, re-drafted document was submitted for a second internal PNL review prior to proceeding further with the formal publication process.

\subsubsection{RPV Research}

The objective of this work is to track the work that is currently being performed under the PISC III program. Of particular interest is the work being conducted in Actions 2 and 3. These actions will provide useful information concerning the capability to inspect nozzles and dissimilar metal welds and begin to address some aspects of the ability of advanced techniques to accurately size flaws and some aspects of the reliability to inspect actual vessels. At this time, there are no results available because the studies cannot be released until the PISC-III management board approves them formally. Draft reports on work of these Actions will be available in early 1993.

Based on the results and data bases from the PISC III program, deficiencies will be identified and a program to provide the necessary supplemental information will be developed and implemented. At this time, this subtask is focused on tracking the relevant PISC III program activities and the results being developed. This has involved reviewing some initial draft reports on some of the studies, but even these will change since the reports are not based on destructive data. Substan- 
tial progress is anticipated to begin during the next reporting period because of the availability of PISC-III reports.

\subsubsection{NDE Requirements for Aging Plants}

Probabilistic fracture mechanics calculations were performed to address concerns with the flaw evaluation procedures given in Appendix A of Section XI for the case of embrittled reactor pressure vessels. The calculations explored the implications of a flaw discovered by inservice inspection, and whether a given flaw of known size is acceptable from the standpoint of pressurized thermal shock (PTS). The results of these calculations indicated that the PTS significance of single known flaw depths as great as two inches has roughly the same risk as the population of flaws assumed for purposes of PTS evaluations. Therefore, the fact that Appendix A does not address PTS transients does not appear to be a major concern - given that the vessel already meets current NRC requirements for PTS risk. A draft report on this work was prepared and submitted for PNL review.

\subsubsection{Future Work}

- PISC II Re-analysis - Following a PNL review of the latest draft report accommodating all of the NRC comments received on the early draft, a final version of this report will be submitted to the NRC for publication during the next reporting period.

- RPV Research - The work planned for the next reporting period will involve reviewing PISC reports and beginning to draft the status report based on reviewing industry efforts to develop the technology to reliably inspect BWR RPVs.

- NDE Requirements for Aging Plants - A report summarizing the results and conclusions of the ASME Section XI flaw evaluation requirements for aging reactor pressure vessels will be completed and submitted to the NRC for comment.

\subsection{Equipment Interaction Matrix}

\subsubsection{Summary}

The goal of this research is to define operating tolerance requirements for UT/ISI equipment that limit the effect of frequency-dependent interactions, thus improving ISI reliability. The objective is to make recommendations for the ASME Code to ensure a reliable inspection. The research for flat plate and piping has been completed and recommendations that resulted have been adopted. The current research extends this work to circular surfaces in order to determine if any changes are needed in the ASME Code requirements for inspections conducted on circular surfaces. The computer code CURVE is running on the SUN Workstation and planning is underway for experimental validation of this computer code.

\subsubsection{Introduction}

The objective of this research is to determine how an ultrasonic inservice inspection of circular steel sections is affected when the performance of one of the components is changed and to develop recommendations for improving the ASME Code. When equipment ages or is damaged, or a component used for an inspection is changed, the system center frequency and/or system bandwidth can change. Such changes can affect the reliability of the inspection and the goal is to determine tolerances on the bandwidth and center frequency to ensure reliability. Research has been completed for flat plates and piping, and a report was published in June 1992, entitled "Development of Equipment Parameter Tolerances for the Ultrasonic Inspection of Steel Components: Application to Components up to 3 Inches Thick" (NUREG/CR-5871). The present research is directed to carrying out similar research for circular steel sections.

\subsubsection{Status of Work Performed}

The code CURVE, dealing with circular surfaces, is running on the SUN Workstation. When the radius has a large value, such as $10 \mathrm{~m}$, the output from CURVE is essentially the same as that from RTOTAL, which is the code developed and validated for a flat plate. This 
expected result validates the code CURVE for the case of large radius.

Planning is underway to test code CURVE experimentally. Two possible methods for experimental validation are: 1) keep the position of the transducer fixed and change the frequency and 2) keep the frequency fixed and change the position of the transducer. The second method was used to validate the code RTOTAL for flat plates and piping. However, in order to use code CURVE effectively for changing the transducer position, a modification of CURVE is needed to carry out the necessary loops in the code. This modification is next on the agenda and will be undertaken by Dan Aalbers, a new SERS student. MS Greenwood has spent time introducing him to the field of ultrasonics, the Equipment Interaction Matrix project, and supervising his work.

\subsubsection{Future Work}

The following work remains to be completed:

- Experimental validation of code CURVE. This will be accomplished by performing pulse-echo experiments with circular sections with the ends cut at different angles.

- Compare results with calculations from CURVE.

- Search for worst-case defects for circular steel sections ranging in thickness from 2 inches to 12 inches.

- Experimentally validate some worst-crse defects.

- Develop ASME Code recommendations. 


\subsection{New Inspection Criteria Task}

\subsection{Summary}

Work continued on assessments of the adequacy of existing ASME Code requirements for ISI and on developing technical bases for improved ISI requirements that will assure an acceptable level of nuclear power plant component structural integrity. Development of a comprehensive probabilistic approach for improved inspection requirements moved forward. A major focus of this effort has been participation in an ASME Research Task Force on Risk-Based Inspection Guidelines. The ASME Task Force has completed a document specifically directed to light water reactor nuclear power plant components "Risk-Based Inspection - Development of Guidelines - Volume 2 - Part 1 - Light Water Reactor (LWR) Nuclear Power Plant Components," and publication as an ASME report is scheduled for December 1992.

Calculations have applied probabilistic risk assessment (PRA) to establish inspection priorities for pressure boundary systems and components. Plant-specific riskbased studies have been initiated for the Surry Unit 1 Nuclear Power Station, with the cooperation of Virginia Electric Power Company. During this reporting period, the ranking of components in the five remaining Surry-1 systems continued with site visits to compile detailed plant information and with analyses of the data from the expert elicitation workshop held in February 1992 to estimate component rupture probabilities for the five systems of interest.

Improved strategies for inspecting the highly ranked piping and vessel components are being developed in collaboration with members of the ASME Research Task Force. Structural reliability calculations have continued with applications of the pc-PRAISE code to predict leak and rupture probabilities for piping in the low pressure injection system and to predict the benefits of alternative inspection scenarios on reducing these probabilities.

\subsection{Introduction}

This task is directed to the development of improved inservice inspection (ISI) criteria using risk-based methods, with the long-range goal to propose changes for consideration by ASME Section XI. These improved critcria will help to establish priorities for selecting systems, components and structural elements for inspection, and will help to determine the extent, frequency, and method of examination. The objective is to develop a technical basis for ISI programs that will ensure a suitably low failure probability, and thus coxtribute in an effective manner to safe nuclear power plant operation.

In past work, we have reviewed and evaluated various concepts for probabilistic inspection criteria, and have interacted with other industry efforts, notably through the ASME Research Task Force on Risk-Based Inspection Guidelines. Starting in FY90 our work has addressed inspection priorities at a detailed component level, and have focused on a pilot study with plant-specific calculations for the Surry Unit 1 Nuclear Power Station. During the previous reporting, period a final ranking of components and associated sensitivity calculations for the first four critical systems (reactor pressure vessel, reactor coolant system, low pressure injection system, and auxiliary feedwater system) were completed. Efforts were also begun to rank components in the remaining five Surry-1 systems of interest (high pressure injection system, residual heat removal system, service water system, component cooling water system, and power conversion system). The initial effort was an expert elicitation workshop held during February 1992 to estimate component rupture probabilities for the five systems of interest. These estimates will be used in future risk-based calculations to develop a complete picture of the most risk significant components within the plant.

A second part of the risk-based inspection work is to identify effective inspection strategies for the highly ranked components that can ensure component failure probabilities which meet target risk goals. Probabilistic fracture mechanics calculations using the pc-PRAISE computer code are being performed to predict the relative benefits of alternative inspection strategies. During the previous reporting period we performed a preliminary set of sensitivity calculations to predict leak and rupture probabilities, and made arrangements for a subcontract with Failure Analysis Associates (the developer of the PRAISE code) for specialized training and guidance in the application of the code. The subcontract was put in place during this reporting period, and PNL staff completed initial training and consultation efforts with $\mathrm{FaAA}$ experts. A matrix of calculations 
was begun and results will be available for presentation and review at the November 1992 meeting of the ASME Research Task Force on Risk-Based Inspection.

\subsection{Status of Work Performed}

\subsubsection{ASME Task Force on Risk-Based In- spection Guidelines}

During this reporting period we have continued to develop approaches for risk-based inspection requirements. Activities in this area have involved Pacific Northwest Laboratory (PNL) participation on a special ASME Research Task Force on Risk-Based Inspection Guidelines, with Dr. F. A. Simonen, Dr. B. F. Gore and Dr. T. V. Vo serving as members of the Task Force. The ASME group has been identified by PNL as an effective route to achieve long-range goals for improved inspection criteria. Recently the Task Force has broken into individual working groups in order to expand its efforts to other non-nuclear industries (e.g. fossil power). As a result, PNL's activities are now limited to the Working Group on Risk-Based Inspection of Nuclear Power Plant Components with Dr. Fred Simonen serving as chairman of this working group. The goal of the nuclear components group is to make recommendations to ASME Section XI on the use of risk-based methods to develop improved inspection programs.

During this reporting period the ASME Research Task Force has been working with the publications staff at the ASME New York office to overcome delays in issuing a document specifically directed to light water reactor nuclear power plants titled "Risk-Based Inspection - Development of Guidelines - Volume 2 - Part 1 Light Water Reactor (LWR) Nuclear Power Plant Components". This document recommends and describes specific methods to be used in developing riskbased inspection plans for nuclear power facilities. Publication as an ASME report is now scheduled for December 1992.

A first step towards impacting ASME Section XI was achieved during this reporting period with the initial meeting in August of a newly formed group which is dedicated to implementation of risk-based inspection into Section XI. Mr. Jack Lance from the Electric Power Research Institute is the chairman of the Imple- mentation Group. Fred Simonen from PNL serves as secretary.

During this reporting period there were two meetings of the LWR Nuclear Power Plant Components Working Group (which reports to the ASME Research Task Force on Risk-Based Inspection Guidelines). These meetings were held on June 24-25, 1992 in New Orleans and on August 13, 1992 in Chicago. Fred Simonen has been preparing and distributing meeting minutes of this working group.

The first meeting in New Orleans included some initial discussions of structural reliability and risk analysis (SRRA) models needed to support risk-based inspection of the low pressure injection system at Surry-1, but mostly addressed longer range concerns regarding implementation of risk-based inspection into Section XI. The main issue concerned the merits of changing the current prescriptive requirements of Section XI versus a more far reaching recommendation that would require a risk-based study based on the PRA for each plant.

The second meeting in Chicago during August consisted of a one day workshop that focused on the low pressure injection system and the SRRA models needed to evaluate alternative inspection strategies. A set of SRRA models was defined to envelop the piping configurations, stress levels and failure mechanisms for the welds, pipe runs and fittings in the LPI system. Members of the working group identified data needed to perform the SRRA calculations and were given assignments to provide data for the probabilistic models.

Future efforts of the ASME Research Task Force will apply the recommended risk-based methodologies to develop improved inspection programs for nuclear power plant components. Results of calculations performed on the new criteria task will be a major contribution to the Volume 2 - Part 2 Document. This document is scheduled for publication during 1994, and will make specific recommendations for consideration by ASME Section XI. 


\subsubsection{Plant Specific PRA Application to Surry-1}

A major part of the new inspection criteria task involves the application of existing probabilistic risk assessments (PRA) to establish inspection priorities for pressure boundary systems and components. During this reporting period a pilot application of PRA methods to the Surry-1 plant continued.

The Surry-1 work has applied a methodology (Vo et al. 1989) that uses the results of PRA's in combination with the techniques of failure modes and effects analysis (FMEA) to identify and prioritize the most risk-important systems and components at nuclear power plants. The specific systems initially selected for analysis were the reactor pressure vessel, the reactor coolant, the low pressure injection (including the accumulators) and the auxiliary feedwater. The risk-based ranking of components within these four systems was completed during FY91, and results were summarized in a previous publication (Vo et al. 1992).

Efforts during this reporting period have addressed the other remaining systems at Surry-1 (high pressure injection, main feedwater, service water, component cooling water, main steam, condensate, and residual heat removal systems). Staff from the Virginia Electric Power Company (VEPCO) have continued to participate in the pilot study, and have thereby assured that the plant models are as realistic as possible and reflect plant operational practices. The final visits to the Surry-1 plant site for walkdowns of the five systems were completed in April 1992. Data from these visits were recorded on FMEA worksheets, but further efforts to rank components in these systems using inputs extracted from the Surry-1 PRA were delayed until the next reporting period.

Future work will result in a comprehensive ranking of all the most important components within the Surry-1 plant systems. These risk-based priorities will permit evaluation of current inservice inspection requirements as specified by Section XI of the American Society of Mechanical Engineers Code. The objective is to identify needed improvements to current ISI plans. These results will be made available to the ASME Research
Task Force as recommendations for consideration by ASME Section XI.

\subsubsection{Expert Judgement Elicitation for Rup- ture Probabilities}

The risk-based studies of the Surry-1 plant have required estimates of rupture probabilities on a detailed component-by-component level. Because neither sufficient data from operating experience nor detailed fracture mechanics analyses are available, the expert judgment elicitation process has been selected as a method to estimate needed rupture probabilities.

PNL conducted the first of two expert judgment elicitation meetings on May 8-10, 1990 at Rockville, Maryland to address the issue of failure probabilities for Surry-1 components. The systems addressed by the first elicitation were the reactor pressure vessel, reactor coolant, low pressure injection (including the accumulators), and auxiliary feedwater. A second workshop held on February 3-6, 1992 in Washington DC addressed Surry-1 components for the high pressure injection system, the residual heat removal system, the component cooling water system, the service water system and the power conversion system.

The second expert elicitation again used a systematic procedure, which closely followed the approach used for the NUREG-1150 PRAs (NRC 1990 and Wheeler et al. 1989). Each of the nine experts completed questionnaire forms that addressed location specific rupture probabilities for the systems and components of interest. The elicited data (for a total of $\mathbf{3 4 5}$ components for the 5 systems addressed) included best estimates of probabilities, uncertainty ranges and an assessment of the effect of aging on the rupture probabilities. During this reporting period, PNL entered the data from the individual expert judgements into a computer data base and performed a preliminary statistical analysis to obtain a single composite estimate for the rupture probability of each component. This initial summary was then mailed to the nine experts of the February workshop, and the experts were asked to review and revise their estimates of component rupture probabilities. Only three of the experts made any revisions to their estimates, and in each case the revisions were relatively minor. All the revised estimates have been 
entered into the computerized data base. Statistical analyses will be performed during the next reporting period, and "bar and whisker plots" will be prepared to display the median values of the estimates along with the range of values provided by the individual experts.

\subsubsection{Structural Reliability Calculations}

The long range objective of the new inspection criteria task is to develop improved inservice inspection plans (what, where, when and by which method) using riskbased approaches. Following the guidelines given in the Volume 2 - Part 1 document issued by the ASME Research Task Force on Risk-Based Inspection, probabilistic fracture mechanics and decision risk analysis methods will be used by PNL in a cooperative effort with other members of the ASME Research Task Force to identify inspection strategies that meet criteria for both safety and cost effectiveness.

To prepare for probabilistic fracture mechanics calculations PNL has worked with members of the Research Task Force, to define potential strategies for inspecting specific components. Structural reliability calculations will determine which of the identified strategies can meet goals of ensuring acceptable failure probabilities. Each of the acceptable strategies will then be evaluated by the Research Task Force using the methods of decision risk analysis to quantify cost/benefit considerations.

The pc-PRAISE code for predicting leak and rupture probabilities has been applied at PNL to predict rupture and leak probabilities for reactor piping, and to predict the effects of inservice inspection on piping reliability. PNL completed subcontract arrangements during May 1992 with Failure Analysis Associates (FaAA, the developer of the pc-PRAISE code). Drs. David Harris and Dilip Dedhia from (FaAA) visited Richland on August 3-4 to provide PNL staff with specialized training and guidance in the application of the code. This workshop session covered methods for predicting failure probabilities of structural components and for predicting the potential reductions in failure rates achicvable by inservice inspection.

PNL has begun work on probabilistic structural mechanics models to evaluate alternative inspection strate- gies for the low pressure injection system. A set of models has been defined to envelop the piping configurations, stress levels and failure mechanisms for the large number of welds, pipe runs and fittings in the LPI system. PNL assembled a set of drawings for the Surry-1 LPI system, and tabulated the pipe diameters and wall thicknesses for all pipe runs of the system. Through discussions with Dr. Ed Rybicki at the University of Tulsa, PNL estimated welding parameters for these sizes of stainless steel piping. PNL forwarded this information to Mr. Vic Chapman at Rolls Royce and Associates with a request that he estimate the numbers and sizes of welding flaws expected for these welds.

Through discussions with Dr. David Harris at FaAA and Dr. Spencer Busin at PNL, PNL addressed the potential for stress corrosion cracking in the LPI systcm. Based on recent work at Argonne National Laboratory this potential for cracking appears to be quite low, unless unexpectedly severe environmental effects exist in stagnant lines. At the end of this reporting period PNL was developing a PRAISE code model to address fatigue that includes effects of through wall secondary bending stresses and weld root stress concentrations. Mr. Ken Balkey at Westinghouse Electric Corporation has been requested to look for information on the "duty cycles" that describe the operational conditions and events for LPI systems.

\subsection{Future Work}

Future activities on the New Inspection Criteria Task will include:

- Continuing support of the ASME Research Task Force on Risk-Based Inspection Guidelines.

- Reduction of the data from the expert elicitation on rupture probabilities for the five remaining systems at Surry-1.

- Probabilistic fracture mechanics calculations to evaluate the effects of inservice inspection on the reliability of vessel and piping components.

- Continuing with the risk-based ranking of components for the final five systems at the Surry-1 nuclear power station. 
Work on this task is proceeding at a somewhat slower pace than expected, due in part to reductions in funding and in part to higher than expected costs of the February 1992 expert elicitation meeting. Risk-based rankings of Surry-1 components will not be completed until next fiscal year.

The long range plan is to continue with pilot calculations and to use the results to focus inspections on the high risk components. Once the Surry-1 studies are complete, future work will evaluate a representative BWR plant. Structural reliability calculations will continue and the results will be used in the development of risk-based inspection programs for the high priority components. As part of the inspection program development we will assign target values of rupture probabilities that are to be maintained by inservice inspection. Working with the ASME Research Task Force we will provide information for use in the decision risk analyses that will identify those inspection strategies that meet criteria for both safety and cost effectiveness. Output from the New Criteria Task will be made available to the ASME Research Task Force on Risk-Based Inspection Guidelines for their use in preparing a document that will recommend risk-based inspection programs for codes and standards consideration. 


\subsection{Consult on Field Problems}

\subsection{Summary}

A trip to Czechoslovakia and Russia was planned to review and assess NDE technologies at institutes in these countries.

Efforts continued to support NRC in the application, validation and modification of the VISA-II fracture mechanics code which predicts the contributions of undetected flaws to the failure of embrittled reactor pressure vessels under conditions of pressurized thermal shock accidents.

\subsection{Introduction}

This task is to provide on-call NDE technical assistance to RES.

\subsection{Status of Work Performed}

\subsubsection{Prepare for Trip to Czechoslovakia and Russia}

It was decided during this time period that potential cooperation between the NRC and organizations and agencies in Czechoslovakia and Russia could be of benefit. PNL staff spent time contacting various people within PNL, at other organizations, and in Europe that have had contact with NDE experts from these countries. This was not easy because of all of the confusion associated with the names of the institutes. Some of the institutes had three or four acronyms. This has led to confusion and made it difficult to quickly decide on where wnyld be the best institutes to visit. Finally, an agenda was prepared and confirmed at the last minute prior to departure. The institutes and personnel to be contacted are shown in Table 5.1.

This trip occurred during the next reporting period and consequently, the insight, understanding and assessment of the activities that occurred on this trip will be covered in the Volume 17 of this series of semi-annual reports.

\subsubsection{VISA-II Code}

PNL continued to support NRC staff in the application, validation and modification of the VISA-II fracture
Table 5.1. Institutes and Personnel to be Contacted during Forelgn Travel

\begin{tabular}{|c|c|c|}
\hline Dates & Institute & Staff \\
\hline $10 / 1-5 / 93$ & $\begin{array}{l}\text { Nuclear Re- } \\
\text { search Institute } \\
\text { and SKODA }\end{array}$ & Dr. Zdarek \\
\hline $10 / 7$ & $\begin{array}{l}\text { Rostov Institute } \\
\text { of Agriculture } \\
\text { Eng. }\end{array}$ & V. Golovin \\
\hline $10 / 8$ & $\begin{array}{l}\text { I.V. Kurchatov } \\
\text { Institute of } \\
\text { Atomic Energy }\end{array}$ & $\begin{array}{l}\text { V. Asmolov } \\
\text { Prof. A. } \\
\text { Tutnov }\end{array}$ \\
\hline $10 / 9$ & NIKIET & $\begin{array}{l}\text { S. Bougaenko } \\
\text { B. Streikov }\end{array}$ \\
\hline $10 / 12$ & Gidropress & $\begin{array}{l}\text { Y. Dragnov } \\
\text { V. Federov }\end{array}$ \\
\hline $10 / 14$ & $\begin{array}{l}\text { CNITTMASH } \\
\text { VNIIAES }\end{array}$ & S. Bougaenko \\
\hline
\end{tabular}

mechanics code. This code predicts the contributions of undetected flaws to the failure of embrittled reactor pressure vessels under conditions of pressurized thermal shock accidents, and has been used by NRC staff and others for plant specific vessel evaluations.

PNL has continued with an ongoing effort to benchmark the VISA-II code against other probabilistic fracture mechanics codes. This work is part of an NRC/EPRI organized group of participants that is performing calculations for a set of PTS benchmark problems. In the previous reporting period PNL assisted in the formulation of the initial set of benchmark problems by revicwing the problen definitions proposed by Westinghouse. PNL also contributed its VISA-II predictions of vessel failure probabilities for these benchmark problems and attended two meetings of the benchmarking group - February 9, 1992 at Atlanta, Georgia and March 23, 1992 at Bethesda, Maryland.

During this reporting period PNL continued to participate in meetings of the PTS benchmarking group. 
Meetings were held on May 6, 1992 in San Antonio, Texas and on August 12, 1992 in Chicago, Illinois. At each of these meetings and through contacts between meetings with other participants PNL has compared its numerical results from the VISA-II code with results submitted by other participants. After evaluating several potential sources for numerical differences, relatively good agreement was obtained among the participants in the benchmarking effort.

One source of significant numerical differences was the use of different procedures for converting continuous distribution functions for flaw deptlis to a discrete format for input to the probabilistic fracture meclianics calculations. Careful attention to detail removed this factor as a source of disagreement. A second source of numerical differences was the use of different assumptions in modeling the random toughness variations that a growing crack encounters as it propagates through the wall of a vessel. PNL modified VISA-II by removing the assumptions that give rise to the random variations in fracture toughness and in this way matched assumptions made in the Westinghouse probabilistic fracture mechanics code. The modified version of VISA-II then predicted fewer crack arrest events and the calculated vessel failure probabilities consistently agreed with the Westinghouse predictions.
As another activity on this task, Fred Simonen participated in an Electric Power Research Institute sponsored workshop on "Application of NDE to Reactor Pressure Vessel Integrity" held on July 16, 1992 in Charlotte, North Carolina.

The main topic of this workshop was the development of improved flaw size distributions from NDE data. PNL presented results from examination of a weld from the Midland vessel and reviewed plans for estimating flaw frequencies for the future examination (using SAFT-UT) of the PVRUF vessel at the Oak Ridge National Laboratory.

\subsection{Future Work}

During the next reporting period PNL will continue to support NRC staff in the benchmarking the VISA-II fracture mechanics code through participation in future industry PTS benchmarking efforts. Other workshop series on topics related to fracture mechanics analyses for pressurized thermal shock scenarios are being planned. An expanded scope of work for PNL has been defined, and as a result future efforts will be funded at PNL by NRC as a separate project beginning in December 1992. 


\subsection{Piping Inspection Task}

This task is designed to address the NDT problems associated with the piping used in light water reactors. The primary thrust of the work has been on wrought and cast stainless steel since these materials are harder to inspect than carbon steel. However, many of the results also pertain to carbon steel. The current subtasks are: cast stainless steel inspection, surface roughness, field pipe characterization, and PISC-III activities.

The work accomplished during this reporting period is summarized in the following paragraphs:

- Cast Stainless Steel Inspection - The objective of this subtask is to evaluate the effectiveness and reliability of ultrasonic inspection techniques on LWR components containing cast stainless steel material. Far-side weld inspection is included in the scope of this work since the ultrasonic field passes through weld metal. Activities for this reporting period included an investigation of low frequency ultrasonic techniques inherently insensitive to macrostructural effects, a fracturc mechanics evaluation aimed at estimating "critical" dimensions of circumferential cracks in CCSS primary pipe sections, and investigating the feasibility of implementing "adaptive ultrasonics" for the inspection of coarse grained materials.

- Surface Roughness Conditions - The objective of this subtask is to quantify and develop requirements to limit the adverse effects of surface conditions upon an ultrasonic inspection. Validation of the first code from CNDE was successfully performed.

- Field Pipe Characterization - The objective of this subtask is to provide pipe weld specimens that can be used for studies to evaluate the effectiveness and reliability of ultrasonic inservice inspection (UT/ISI) performed on BWR piping. Processes to dispose of these samples are still under review to meet the new requirements for disposal required by state and federal agencies. Estimates of costs are needed so that funding can be identified to perform the work.

- PISC-III Activities - This activity involves participation in the PISC-III program to ensure that the work addresses NDE reliability problems for ma- terials and ISI practices on U.S. LWRs. This includes support for the co-leader of Action 4 on Austenitic Steel Tests (AST); providing a sector of the Hope Creek reactor pressure vessel containing two recirculation system inlet nozzles; coordination of the inspections to be conducted by U.S. teams on the various actions; input to the studies on reliability and specimens for use in the parametric, capability, and reliability studies of the AST. During this reporting period, plans were being finalized for the wrought stainless steel reliability study that involves testing in the USA.

\subsection{Cast Stainless Steel Inspection}

\subsubsection{Introduction}

The objective of this task is to evaluate the effectiveness and reliability of ultrasonic inspection of cast materials used within the primary pressure boundary of LWRs. Due to the anisotropic and nonhomogeneous nature of coarse-grained cast materials, reliable and effective ultrasonic inspections are difficult to perform. The large grain size relative to the acoustic pulse wavelength strongly affects propagation of ultrasound by causing severe attenuation (primarily due to scattering), significant changes in acoustic velocity, and mode conversions. Refraction and reflection of the sound beam may occur at the grain boundaries, resulting in field skewing and partitioning. This leads to poor signal-to-noise ratios, false reporting of defects, incorrect reporting of defect location, and failure to examine specific volumes of the material.

These inspection problems are common to structures such as cladded pipe, inner-surface cladding of pressure vessels, statically cast elbows, statically cast pump bowls, centrifugally cast stainless steel (CCSS) piping, dissimilar metal welds, and weld-overlay-repaired pipe joints.

CCSS piping is used in the primary reactor coolant loop piping of 27 pressurized water reactors (PWRs) manufactured by the Westinghouse Electric Corporation. However, CCSS inspection procedures continue to perform unsatisfactorily due to the coarse macrostructure that characterizes this material. The major macrostructural classifications are columnar, equiaxed, and a 
mixed columnar-equiaxed macrostructure. The majority of field material is believed to be the latter.

\subsubsection{Status of Work Performed}

The work described during this reporting period falls under three categories: development of low frequency inspection techniques, development of an adaptive ultrasonic phase compensation algorithm, and fracture mechanics calculations and analysis. The work described here was performed in order to provide a firm engineering basis for evaluating and recommending the possible utility of two inherently different ultrasonic techniques used for inspection of coarse-grained materials. The concept behind the work is to investigate low frequency ultrasonic techniques inherently insensitive to macrostructural effects, to utilize fracture mechanics evaluations on CCSS in order to establish guidance for the sizes of flaws that need to be reliably detected, and to examine the utility of a technique developed in optics, by experimentally implementing adaptive ultrasonic methods in crder to compensate for random time shifts induced by the inhomogeneous material structure.

Work described during this reporting period continued with the acquisition of new sets of $\mathrm{rf}$ ultrasonic data of an entire flaw located in a columnar sample for use in assessing adaptive UT processing. The sample specimens used for this work have been etched and photographed for documentation purposes. Primary parameters including temporal sample rate and spatial sampling were changed to $100 \mathrm{MHz}$ and 25 mils, respectively. The results (phase compensation) were significantly improved. The wavefront compensation plots were smoothed by fitting the initial plot of time shift vs. position to a polynomial. Completion and finalization of the processing and visualization software is currently underway.

A transducer design/fabrication meeting was held with GJ Posakony and Gary Langlois (Sigma Transducers) in order to properly plan the implementation of search units for low frequency UT on CCSS. It was decided that the low frequency inspection would utilize normal, 30,45 and 60 degree incident longitudinal waves in the pulse-echo and pitch-catch modes with $1^{\prime \prime} \times 2^{\prime \prime}$ rectangular transmit-receive elements. The piezoelectric materials will be lead metaniobate (transmitter) and PVDF (receiver). The decision to purchase a custom-designed search unit was experimentally verified by examining all other avenues, including utilization of a variety of largediameter, low-frequency Airmar transducers. These units were applied to carbon steel, water, and CCSS; and the limiting factor was pulse length (narrow bandwidth) that essentially created a "dead zone" that extended nearly all the way through the specimen and made it impossible to uiscern flaw/crack signals.

Due to DOE purchasing guidelines, PNL was unable to initiate purchase requisitions in a timely manner. Procurement of the low frequency search unit was delayed by over two months, delaying work and milestones.

After receiving the transducers in July, initial testing of the transducers resulted in the de-bonding of the PVDF receiving element from the weal plate. The element was sent back for repair, which delayed work another month.

In addition, an arbitrary waveform generator was made available for use on cast material inspection. This instrument improved the temporal response of low frequency transducers by providing the capability to implement inverse filters.

The data acquisition system for obtaining A-scan data on the various CCSS sample specimens was assembled and optimized. The size of the transducer presented some initial problems with regard to coupling and maximization of scan area, but these problems were overcome by implementing an immersion inspection. Initial work included optimization of the driving parameters of the arbitrary waveform generator. Scans on a carbon steel reference specimen (of a fabricated $50 \%$ through wall notch, and of the corner reflection) were acquired as a function of the following:

\section{- Frequency}

- Macrostructure (average grain diameter, grain orientation etc.)

- Pulse Length, Shape, Width, etc.

- Inspection Angle (angle of incidence: 30, 45 and 60 degrees)

This testing regimen was also used to establish criteria for the examination of the CCSS specimens. Numerous A-scans were acquired on a variety of CCSS samples, and showed encouraging results with regard to signalto-noise ratios and search unit performance. From these initial results, PNL decided to examine two speci- 
mens used in the Centrigually Cast Stainless Steel Round Robin Test (CCSSRRT) PISC-III study more thoroughly. This work will be reported in the next semi-annual report.

Work with fracture mechanics evaluations of CCSS is being performed by Fred Simonen. Fred's approach is to utilize work performed at Battelle-Columbus and ANL in performing calculations to estimate dimensions of critical cracks in CCSS. The objective of the fracture mechanics study is to assemble and interpret information on the fracture of cast stainless steel components in order to make recommendations regarding the sizes of flaws that need to be detected for an effective inspection of cast materials. It was realized that current and even advanced UT methods will not detect flaws of the smaller sizes that can be readily detected in other materials. The detection of small flaws in cast materials remains a long-range goal for NDE development. Nevertheless, it is also important to establish what sizes of larger flaws are still below critical sizes for typical cast components, since significant benefits can be achieved if the NDE methods can detect these larger flaws.

An in-depth literature search and review of current work on CCSS fracture mechanics evaluations was completed, and industry contacts resulted in providing little information useful to this study due to proprietary reasons. The bulk of this work contained summaries and descriptions of work performed at ANL on definitive lower bound J-R fracture curves for thermally aged CCSS. Estimates of critical flaw sizes for primary coolant piping using Argonne's toughness data, published data on piping loads, and one of Battelle-Columbus's methodologies have been completed. Service loads on PWR primary coolant piping are relatively low, and thus even severely aged CCSS can tolerate $50 \%$ through-wall circumferential short flaws.

\subsubsection{Future Work}

CCSS work for the next reporting period will focus on finalization of experimental work for the assessment of low frequency UT detection techniques on coarsegrained specimens, an evaluation of the utility of cross correlational processing (adaptive UT) including documentation and final software refinement, and final reporting of the fracture mechanics evaluations on
CCSS. Culmination of this work will result in an overall assessment of the two techniques, and a letter report documenting all FY 92 work on coarse-grained material inspection.

\subsection{Surface Roughness Conditions}

\subsubsection{Introduction}

The objective of this task is to quantify and develop surface finish requirements to limit the adverse effects of surface conditions upon an ultrasonic inspection. To achieve this objective, there has been a cooperative effort between PNL and the Center for Nondestructive Evaluation (CNDE) at Iowa State University (ISU). An isotropic model was developed at CNDE, with EPRI funding; and this model is being validated at PNL, with NRC funding. Once this model is validated, the model will be extended to include a pulse-echo arrangement with subsequent validation at PNL. The goal is to use the model as an engineering tool to study effects of any type of surface condition.

When the experimental data were compared with theoretical calculation, good agreement resulted for shear and longitudinal wave propagation and for several different step discontinuities. From these results, PNL concludes that the theoretical model has been successfully validated.

\subsubsection{Status of Work Performed}

Work continued toward the development of surface specifications for ultrasonic inservice inspection of LWR piping and reactor vessels. At the Quantitative Nondestructive Evaluation conference, held at the University of California at San Diego from July 19-24, 1992, M. S. Greenwood presented a paper entitled "Ultrasonic Propagation through a Surface with a Step Discontinuity: Validation of a Hybrid, Gauss-Hermite Ray Tracing Beam Model." In this paper, included as Appendix A to this report, the experimental data obtained at PNL were compared with the latest theoretical model developed at CNDE. The results, presented in Fig. 3 of Appendix A, show very good agreement for normal incidence of the ultrasound beam upon the $0,10,30$, and 60 mil steps. The data for $45^{\circ}$ longitudinal propagation, shown in Figs. 4 and 6 of Appendix A, show very good agreement with the theoretical calculations 
for the 0 and 10 mil steps; and good agreement for 30 and 60 mil steps. When the experimental data for the $45^{\circ}$ shear propagation was originally compared with the theoretical calculations, the agreement was not very good. However, an error in the computer code was discovered (in one line an $\mathrm{L}$ should have been an S) and when this was corrected, excellent agreement resulted as shown in Figs. 5 and 7 of Appendix A.

Two sets of experimental data were obtained and there was very good agreement between them. The slight differences between them can be attributed to a slightly different alignment of the transducer bracket relative to the steel plate.

The experimental data has been analyzed in two ways, and one of them is a new method for analyzing such data at PNL. The first method is the standard one of selecting a gate within the A-scan and obtaining the largest amplitude within that gate. The result is called a composite C-scan. In the second method, the A-scan (voltage versus time) is fast Fourier transformed (FFT) to yield amplitude versus frequency. The amplitude at $2 \mathrm{MHz}$ can then be accurately obtained. The results of these two methods were compared and generally the agreement was very good, but the minima in the plots of the experimental data were slightly deeper for the FFT method. In these experiments we used 4-cycle and 8-cycle tone bursts, but the FFT methods can also be used for 1-cycle tone bursts or a square pulse where the composite C-scan method would not be valid. The programs for the FFT analysis were written for the SUN Workstation, using the PV-WAVE software.

The analysis of the data was accomplished using a revised version of the code provided by CNDE to PNL. In this code the transmission of the ultrasound from the bottom surface through the water is included. This is necessary because the microprobe measuring the pressure amplitude is located about $2 \mathrm{~mm}$ below the bottom surface.

The surface with the step discontinuity is described by a grid of points and the $z$ value describes the height of the surface at each point. It was found that the theoretical curve is dependent somewhat upon the distance between the grid points. Initially, the distance was 0.12 $\mathrm{cm}$ and this value has been decreased to $0.03 \mathrm{~cm}$. The grid points are used in the ray-tracing part of the code.
The angle at which the ultrasound strikes the top surface containing the step discontinuity must be very accurate, because that value determines the angle of propagation within the steel. In the second set of experimental data, the locations of the reverberations of the ultrasound with the steel plate were obtained. These results led to the measurement of the angle. We were able to check the angle for shear wave generation and confirm that the transducer bracket for the shear wave was machined with sufficient accuracy.

The comparisons between the experimental data and the calculations obtained from the computer code are very good. The conclusion is that the theoretical model has been validated.

\subsubsection{Future Work}

Now that the first model has been validated, the next step in the model development is to consider a pulseecho arrangement. In this case, the transducer and steel plate will be placed in an immersion tank. The transducer will insonify a step discontinuity on the top surface and the ultrasound will be reflected by a perpendicular notch. The following are parameters that can be varied: 1) the height of the step discontinuity, 2) the distance between the step and the notch, and 3) the height of the notch.

\subsection{Field Pipe Characterization}

\subsubsection{Introduction}

The objective of this subtask is to provide pipe weld specimens that can be used for studies to evaluate the effectiveness and reliability of ultrasonic inservice inspection (UT/ISI) performed on BWR piping. Five safe-ends removed from the Monticello nuclear power station are no longer needed for any programmatic work. Processes to dispose of these samples are still under review to meet the new requirements for disposal required by state and federal agencies.

\subsubsection{Status of Work Performed}

This task is completed except for the disposal of the 5 safe-ends that were acquired on this task. This is not as simple a matter as in the past since the specimens are radioactive and because of the lead that was 
wrapped around the specimen for shipment, these are considered mixed waste. Review of new requirements for disposal and the funding to cover the costs are the issues being examined at this time. When the information gathered is sufficient that specific recommendations for a course of action can be proposed to the NRC, then this will be done and a plan established for conducting the disposal.

\subsubsection{Future Work}

Bury the safe-ends as soon as possible.

\subsection{PISC-III Activities}

\subsubsection{Introduction}

The objective of this subtask is to contribute to the international Programme for the Inspection of Steel Components III (PISC III) to facilitate current studies on the reliability, capability, and parametric analysis of NDE techniques, procedures, and applications. This includes full-scale vessel testing; piping inspections; human reliability, real components, nozzles and dissimilar metal welds; and modeling studies on ultrasonic interactions. The data will be used in quantifying the inspection reliability of ultrasonic procedures and the sources and extent of errors impacting reliability.

The primary areas in which PNL participated include Action No. 1 on Real Contaminated Structures Tests (RCS), Action No. 2 on Full-Scale Vessel Tests (FSV), Action No. 3 on Nozzles and Dissimilar Metals Welds (NDM), Action No. 4 on Round-Robin Tests on Austenitic Steels (AST), Action No. 6 on Ultrasonic Testing Modeling (MOD), and Action No. 7 on Human Reliability Exercises (REL). These actions are being followed to ensure that conditions, materials, and practices in the U.S. are being included in the work so that the results are transferable to the U.S.

\subsubsection{Status of Work Performed}

A number of activities have occurred during this reporting period. Several PISC III meetings were attended to present status of work performed on Action 4 and to review and assess the activities on the other actions. It is important to understand that the PISC III program will be completed at the end of the calendar year 1993.
This has placed an urgency on keeping programs on track and having participants provide results according to the PISC III rules which is within three months following the completion of the inspections performed.

A PNL representative, J. C. Spanner, travelled to the Risley Engineering Laboratories in Cheshire, England on August 28-September 12, 1992, to serve as an invigilator for the PISC-III Human Reliability Studies (all travel costs were covered by the International PISC-III Programme office).

The work of an invigilator was to monitor the testing of an inspector while he performed inspection tasks in a controlled environment. This included a laboratory called a "TEL" that permitted the lighting, temperature, humidity, and background noise levels to be adjusted to better simulate the conditions found in an LWR inspection environment. The inspector performed tasks based on specific procedures and this included calibration, inspections on a simulator, monitoring of all movements with several TV cameras, continuous monitoring of the inspector's body temperature, and an interview at the beginning and end of each day. This is an important study and our assessment is that this is a very well designed study. Our assessment is that this will be very informative and provide some insight into the inspection process and the variability that is to be expected. Perhaps some ideas on areas where improvements can be made will be found. However, it is expected that this study will do more to demonstrate the severity of the problem than to provide solutions.

During this reporting period, the team data for teams from the USA which inspected the wrought stainless steel capability specimen set were reviewed and deficiencies identified. The teams were then contacted and clarification or corrections sought. Of the eight teams that performed inspections, six teams provided high quality and well documented data. One team had data that became corrupted and unuseable before the analysis could be performed, but after the inspections had all been completed and the specimens shipped to the next company. Another team turned in raw data with no interpretation or data reduction which made their contribution of little value.

The schedules for the cast-to-cast and the cast-towrought specimens was reconfirmed and everything set 
in motion for these two specimen sets to be in the USA during the first three months of calendar year 1993.

In preparation for the wrought stainless steel reliability study, a problem had arisen because no teams volunteered to participate in this study. As a consequence, a request for proposal was prepared to fund teams to participate with the request that cost sharing was highly desirable. This request for proposal was submitted to the PNL contracts organization. During this reporting period, the request was sent out to perspective inspection companies. Contracts will be placed during the next reporting period and the inspection performed. Following the inspections by three USA teams, the specimens will be sent to the Joint Research Centre in Petten, Holland for the teame in Europe to conduct their inspections.

The Data Analysis Group (DAG) for Action 4 had its first meeting in Venice, Italy and Steven Doctor, the coleader of Action 4, was selected to be the DAG 4 chairman. During this first meeting, many organizational factors were dealt with. It was noted that to do an effective job on data analysis, it is imperative that all DAG members memorize all the defects and their attributes. Of course, in order to do this, destructive results must be provided on each intentional and unintentional flaw. It was decided that flaws less than 1 $\mathrm{mm}$ in size would not be destructively analyzed. This is a practicality point because otherwise it can be prohibitive from both a cost and a time schedule standpoint. This next year the DAG 4 will be very busy analyzing the three capability studies and the two parametric studies that have been conducted as part of this action.

\subsubsection{Future Work}

The following activities will be performed:

- Attend PISC III Management Board meetings

- Chair DAG 4 meetings

- Co-ordinate cast-to-cast and cast-to-wrought circulation schedule in the USA

- Place the contracts for three teams to conduct the inspections on the wrought stainless steel reliability study

- Set up the inspection site for the reliability study and conduct the testing

- When wrought stainless steel capability data is received, begin conducting ROC analysis on this data set. 


\subsection{References}

Vo, T. V., B. F. Gore, L. J. Eshbach, and F. A. Simonen. 1989. "Probabilistic Risk Assessment-Based Guidance for Piping Inservice Inspection." Nuclear Technology, Volume 88 (1), American Nuclear Society, La Grange Park, Illinois.

Vo, T.V., B.W. Smith, F.A. Simonen, and S.R. Doctor. 1990. "Development of Generic In-Service Inspection Priorities for Pressure Boundary Systems," Nuclear Technology, Volume 92 (291), American Nuclear Society, La Grange Park, Illinois.

Vo, T.V., B.F. Gore, F.A. Simonen, and S.R. Doctor. 1992. "Development of Generic In-Service Inspection for Light Water Reactors," Fatigue Fracture and Risk1992, PVP-Vol. 241, pp. 109-117, American Society of Mechanical Engineers, New York, New York.
U.S. Nuclear Regulatory Commission (NRC). 1990. Severe Accident Risks: An Assessment for Five U.S. Nuclear Power Plants. NUREG-1150, Volume 1, Final Summary. Nuclear Regulatory Commission, Washington, D.C.

Wheeler, T. A., S. C. Hora, W. R. Cramond, and S. D. Unwin. 1989. Analysis of Core Damage Frequency from Internal Events; Expert Judgment Elicitation. NUREG/CR-4550, Volume 2. Sandia National Laboratories, Albuquerque, New Mexico. 


\section{Appendix A}

\section{Ultrasonic Propagation through a}

Surface with a Step Discontinuity: Validation

of a Hybrid, Gauss-Hermite Ray Tracing Beam Model 


\title{
Appendix A: Ultrasonic Propagation through a Surface with a Step Discontinuity: Validation of a Hybrid, Gauss-Hermite Ray Tracing Beam Model
}

\author{
ULTRASONIC PROPAGATION THROUGH A SURFACE WITH A STEP \\ DISCONTINUITY: VALIDATION OF A HYBRID, GAUSS-HERMITE RAY \\ TRACING BEAM MODEL
}

M. S. Greenwood and J. L. Mai

Pacific Northwest Laboratory*

Richland, Washington 99352

\author{
A. Minachi, 1. Yalda-Mooshabad, and R. B. Thompson \\ Center for Nondestructive Evaluation \\ lowa State University \\ Ames, lowa 50011
}

\section{INTRODUCTION}

This research continues our cooperative effort to study the effects of largescale surface roughness on ultrasonic transmission through interfaces and updates our previously-reported results [1]. The Center for Nondestructive Evaluation has developed a model for the propagation of ultrasound through a surface and into an isotropic metal and this model is undergoing experimental validation at Battelle PNL. Once validated, this model will be used as an engineering tool to study the effects of surface conditions upon an ultrasonic inspection of nuclear reactor components. The goal is to quantify and develop requirements to limit the adverse effects of surface conditions during such an inspection. Currently, there are no ASME Code requirements dealing with surface conditions during an UT inspection. Commonplace in the field are abrupt step discontinuities on the order of $1.5 \mathrm{~mm}$. M. S. Good [2] has measured up to a $12 \mathrm{~dB}$ signal loss from a $10 \%$ through-wall notch due to a $1.5-\mathrm{mm}$ step.

In order to see how a step discontinuity affects an ultrasonic inspection, consider the situation shown in Fig. 1 in which a transducer travels across a 0.061 inch step on a 0.596 -inch thick plate. Couplant gel occupies the space between the probe and the metal surface. The path of the central ray is shown as it refracts at the plastic-gel interface and the gel-metal interface. So that the tip of the transducer can reach the top of the step, the transducer must he rotated by 3.02 . A calculation shows that point $P$ moves a distance of 0.16 inches during this rotation and also that the pulse-echo time increases by 2.8 microseconds [3]. Therefore, the rotation of the transducer, even by such a seemingly small amount,

*PNL is operated for the U.S. Department of Energy by Battelle Memorial Institute. 


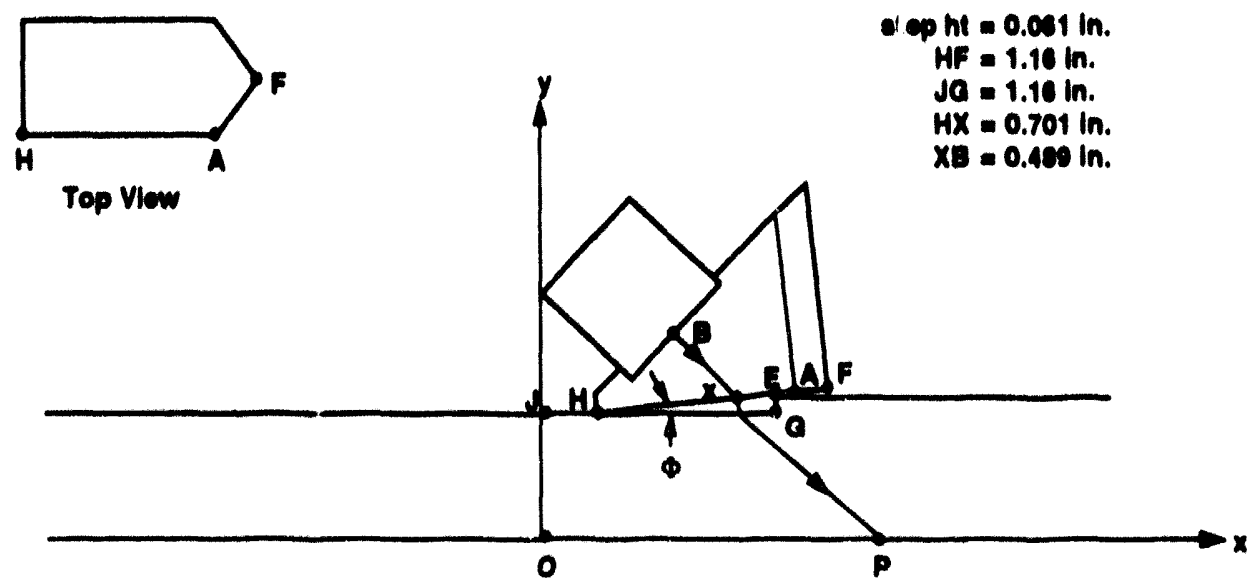

Fig. 1. Transducer crossing a step discontinuity 0.061 inches $(1.5 \mathrm{~mm})$ high on a plate 0.596 inches thick.

results in some areas not being scanned effectively by the central ray of the transducer.

\section{ISOTROPIC MODEL: RECENT IMPROVEMENTS}

Reference 1 and the references cited therein provide a description of the hybrid, Gauss-Hermite ray tracing beam model. The experimental set-up, which will be described in more detail shortly, is shown in Fig. 2 and we shall compare the pressure measured by the microprobe with the predictions of the model. For the pressure generated by the transducer, we expand an assumed piston profile in a series of Gaussian-Hermite basis functions, whose laws of propagation, known analytically, are used to predict the beam profile incident on the interface. A raytracing model is then used to approximate the change in the beam as it propagates across the irregular interface. Just past the interface, the fields are reexpressed in terms of the Gaussian-Hermite beam model, which is used to describe the subsequent propagation to the lower surface. The output of this initial version of the code gives the amplitude versus the $x$-coordinate using the coordinate system described in Fig. 2, with the effect of the lower metal surface being neglected (i.e., the fields are predicted as if the medium were serni-infinite).

The step discontinuity is described by a square grid of points using a coordinate system with an origin at the top of the step. The grid points range from $x$ (and $y$ ) between $-3.0 \mathrm{~cm}$ to $3.0 \mathrm{~cm}$ with a grid point separation of $0.03 \mathrm{~cm}$. The $z$ coordinate describes the height of the step at each grid point, where $z=0$ when $x$ is positive and $z=-$ (step height) when $x$ is negative. These grid points are used in the ray tracing part of the code.

A recent improvement involves propagating waves from the metal into the water below the plate, using a procedure similar to that employed at the entry surface. Surfaces of constant phase determine the direction of the rays that strike the bottom surface of the metal and transmission coefficients yield the amplitude 


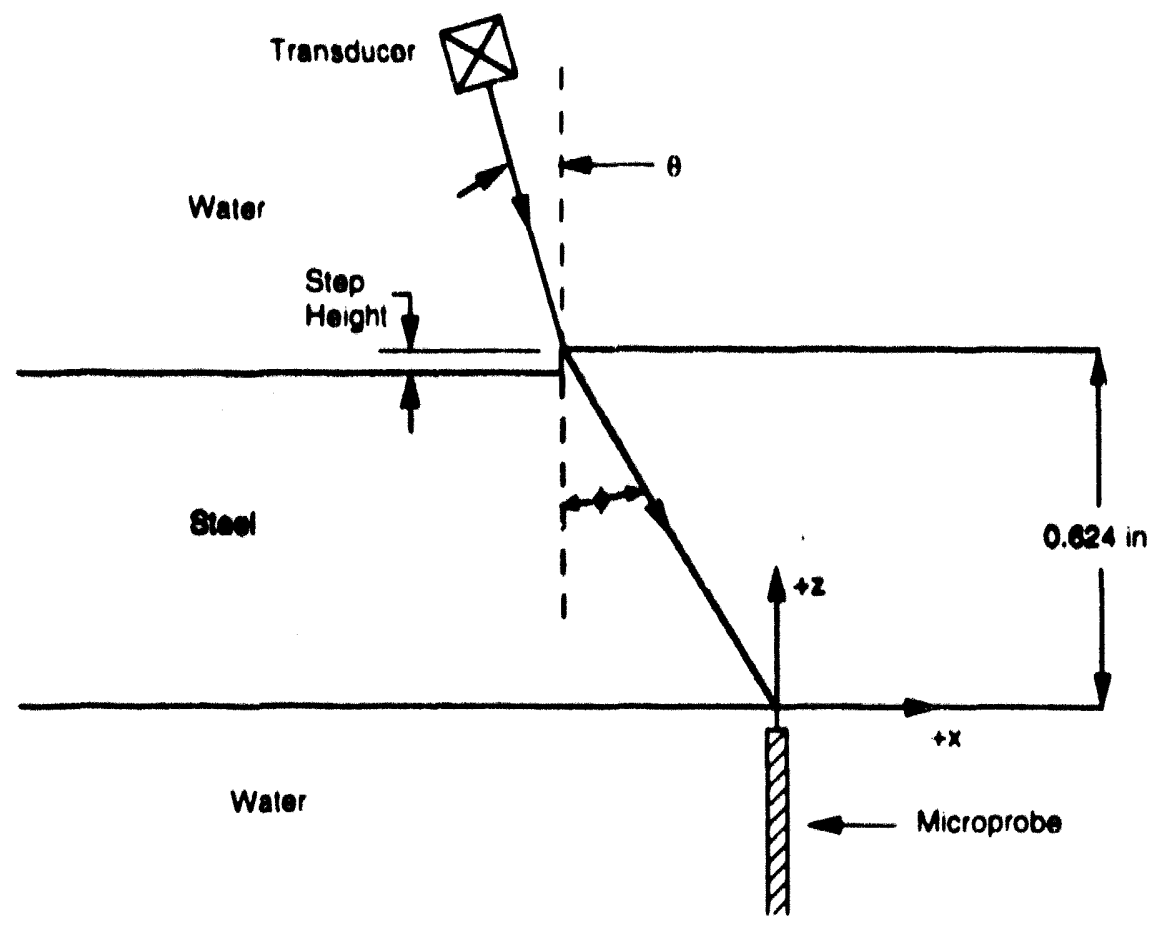

Fig. 2. Schematic diagram of the experimental set-up.

in the water. Since the transmission coefficients are a function of the angle of the ray the pressure in the water is not simply proportional to that on the bottom surface of the plate. The results of some calculations show that, for longitudinal waves, the principal effect is to reduce the amplitude somewhat when $x$ is greater than zero.

\section{EXPERIMENTAL OBSERVATIONS}

\section{Data Set I}

A schematic diagram of the experimental set-up is shown in Fig. 2. The steel plate, having a thickness of 0.624 inches $(1.585 \mathrm{~cm})$, contains three steps: 10 mils $(0.0254 \mathrm{~cm}), 30$ mils $(0.0762 \mathrm{~cm})$, and 60 mils $(0.1524 \mathrm{~cm})$. A 0.5 -inch diameter transducer produced ultrasound having a frequency of $2.0 \mathrm{MHz}$. The transducer was mounted on a plexiglas bracket that was designed to produce the desired incident angle $\boldsymbol{\theta}$ and the bracket was fastened to the steel plate. The distance between the center of the transducer and the top of the step was $6.3 \mathrm{~cm}$ for the normal orientation, $6.4 \mathrm{~cm}$ for $45^{\circ}$ longitudinal wave generation, and 6.7 $\mathrm{cm}$ for $45^{\circ}$ shear generation. A microprobe, 10 mils in diameter, was attached to a laboratory $x$-y scanner and used to measure the pressure over a 2 inch $\times 2$ inch scan, every 10 mils in the $x$ and $y$ directions at a distance $3 \mathrm{~mm}$ below the bottom surface. 
When the incident angle $P$ (defined in Fig. 2 ) is $10.4^{\circ}$, a longitudinal wave $\left(\Phi=45^{\circ}\right)$ as well as a shear wave $\left(\Phi=21.7^{\circ}\right)$ are produced in the steel. Herc we used a 4-cycle tone burst to excite the transducer. When the incident angle $\theta$ is $20.2^{\circ}$, only a shear wave $\left(\Phi=49^{\circ}\right)$ is produced in the steel and we used an 8 cycle tone burst. When the heam was directed normal to the step, we also used an 8 cycle tone burst.
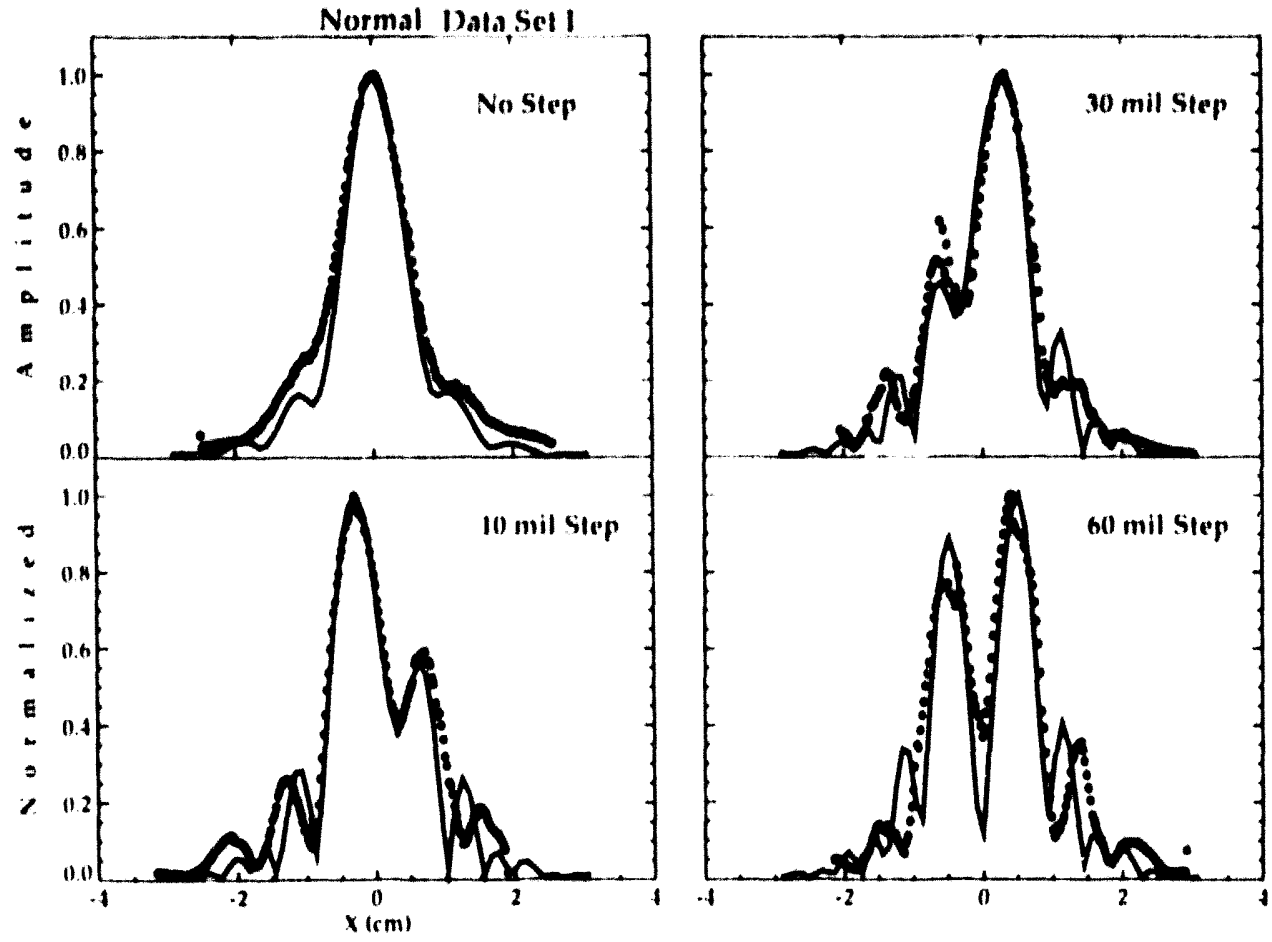

Fig. 3. Comparison of experimental data (Data Set I) with theoretical calculations for the normal orientation. In this figure, and all that follow, the experimental data are indicated by solid circles and the theoretical curves, by a solid line.

\section{Separation of Longitudinal and Shear Sizials}

When the incident angle is $10.4^{\circ}$, hoth longitudinal and shear waves will be produced in the steel. Each can be detected by the microprobe. One certainly needs 10 assess under what conditions the re might be interference between these two signals.

Consider a longitudinal wave generated in steel at an angle of $45^{\circ}$ and a shear wave at $21.7^{\circ}$ and assume that they are plane waves. For a thickness of $0.624 \mathrm{in}$, a calculation shows that the shear signal will arrive at the microprobe 3.0 microseconds after the longitudinal signal and that this time is independent of the position of the microprobe. For this reason, we used a 4 cycle tone burst ( 2 microseconds in length) in obtaining the longitudinal data at $45^{\circ}$. 
Dilla Aralusis

The A.scan data were analyzed in two ways: 1) using a gated composite (: scan and 2) a fast fourier transform (fIFT) analysis. In the first method a point is selected on the $A$-scan and the software selects similar points on all of the $A$. scans. Then a gate of a certain widh (here, 1 micresecond) in selected and is centered over the point. The soffware selects the maximum amplitude of the $A$. scall signal within the galle. We also decided to develop a FFI analysis applicalble to the SUN Workutation. We andilyzed data using both methods and found that there is very little difference in the results. However, H:T andlysis capability permits us (1) use a type of signal other than a tone hurst to excite the tranducer.

Figures 3 through s show the comparison of the experimental data ohtained from the Firl analysis with the theoretical calculations. Care was laken to consure that the experimental data were placed appropriately upon the theoretical calculations by determining the location of the step for both theory and experiment. When the data were taken, the microprobe was moved to the location under the step and its position in the scan was recorded. Figure 2 shows the location of the step relative to the origin of the coordinate syotem, which is used for the theoretical calculations.

\section{Data Selll}

A second set of data was also obtained. Esentially the same experimental set-up was used, but at negative bi-polat pulse (1 cycle) was applied to the transducer. The pulse width was 0.44 mieroseconds and the pulser output voltage was $375 \mathrm{~V}$. The resulting $\mathrm{A}$-scam were andlyad wing the FrT-method The $\mathrm{A}$. wan were obtained by incrementung the baboratory $x \cdot y$ seanner by $0.03881 \mathrm{~cm}$.

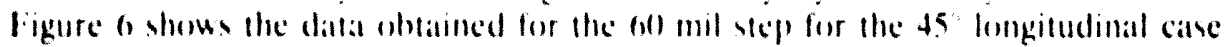
and lig. 7, for the 45 shear cate for all sepe

\section{DISC ISSSION}

Figure 3 shew very good agreement between the experimental data for the normal orientation (Data Set D) and the theoretical calculatiom for all of the steps. Comparison with Reference I hows that the two sets of data agree very well and within experimental uncertainties. (One alos notes that the recently. modified theory gives an improved fit to the datti.

When comparing the data shown in Fig. 4 for the 45 longitudinal case with that shown in Reference 1, one sees comparable results for the 10 mil sep. llowever, for the 30 and 60 mil steps the data in Reference I how a sizeable secondary peak to the right of the main peak while in Datlat Set I only traces of this secondary peak are evidem. The data for the 310 mil and 60 mil steps in Reference I were re-examined. A composite ( scall was obtained by placing a gatte of 10.7 microseconds over the first cycle of the eight eycle tone burst This type of gating was used to eliminate any interference between the longitudinal and shear waves. The results were the same as reported in Reference 1.

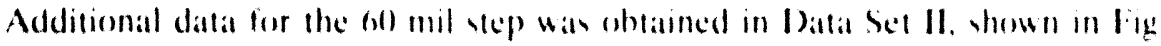
6. and here we see as stong secondary peak. esen stronger than in Reference l. The most likely explanation for these differences is at vlightly defferemt orfentation 


\section{Appendix A}
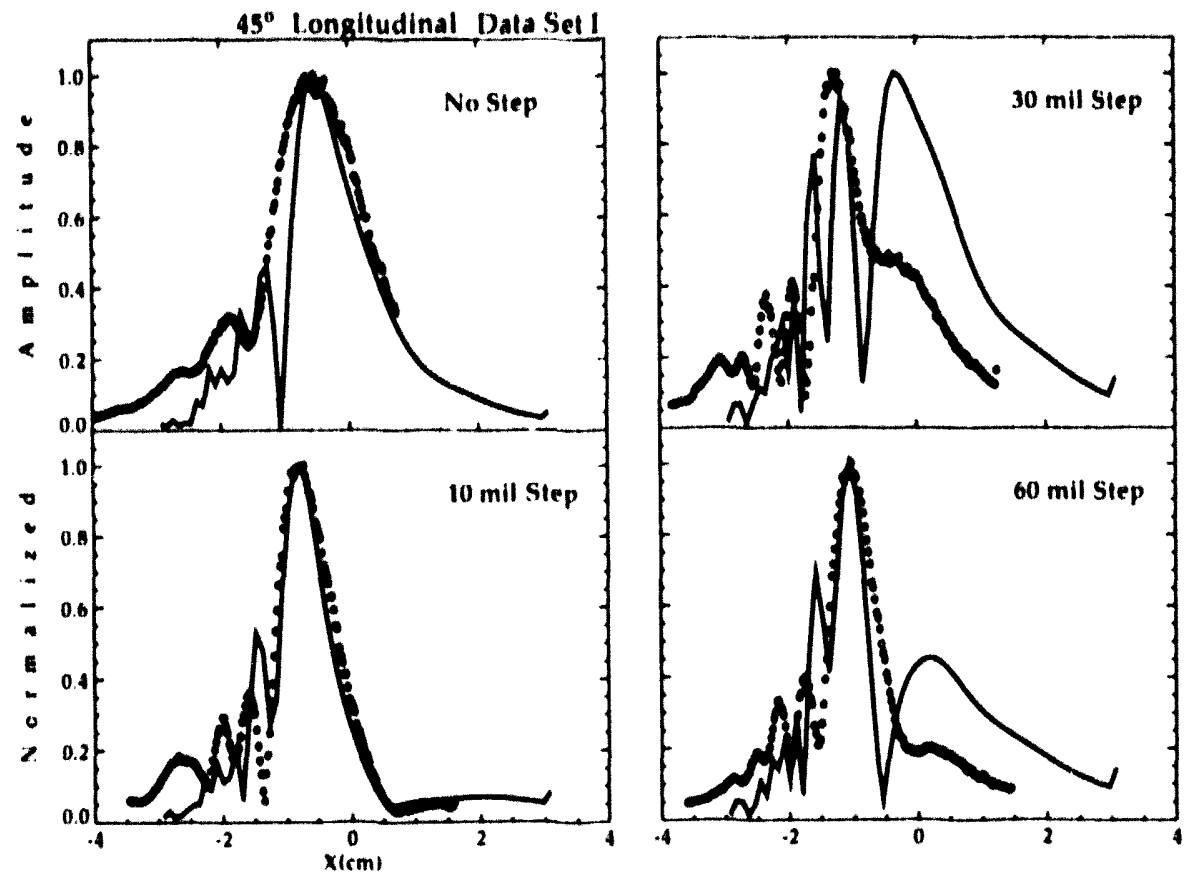

Fig. 4. Comparison of experimental data (Data Set I) with theoretical calculations for $45^{\circ}$ longitudinal waves.
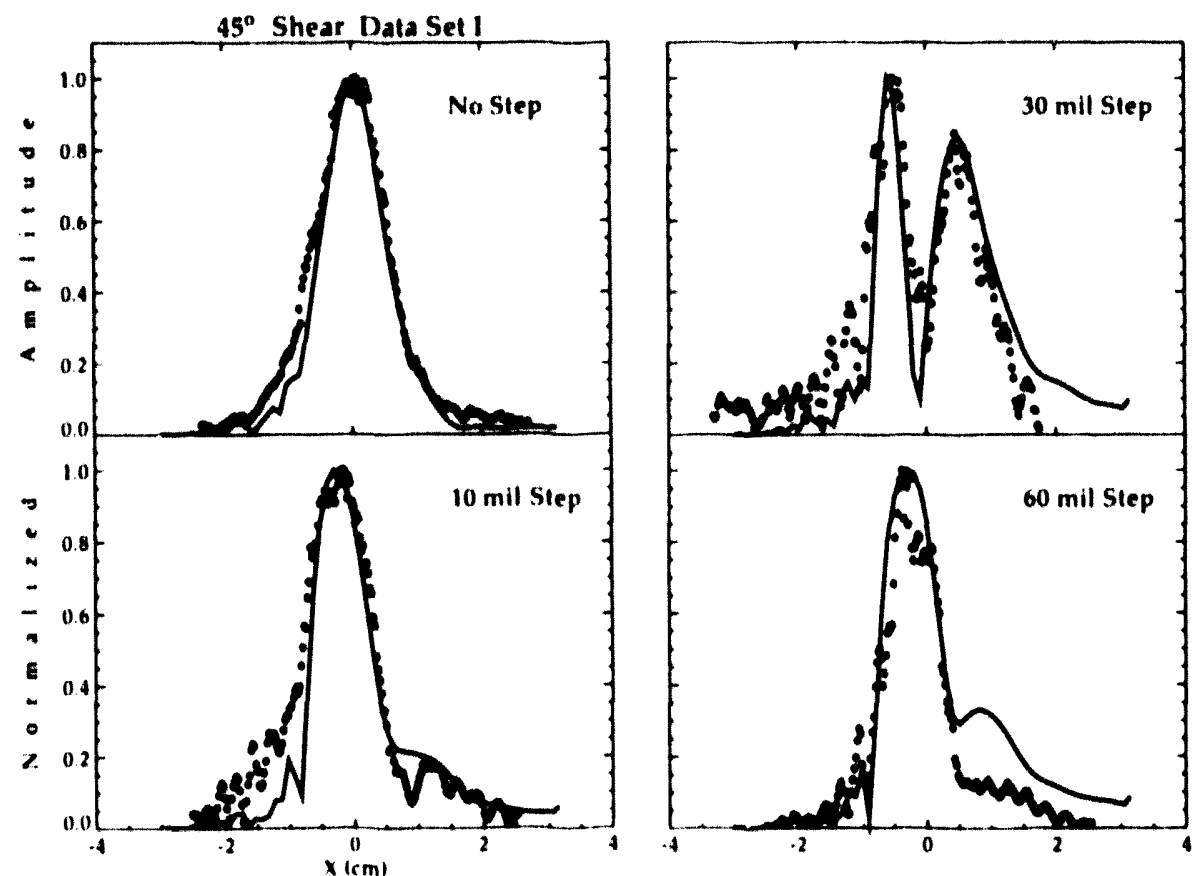

Fig. 5. Comparison of experimental data (Data Set $l$ ) with theoretical calculations for $45^{\circ}$ shear waves.

208 
Appendix A

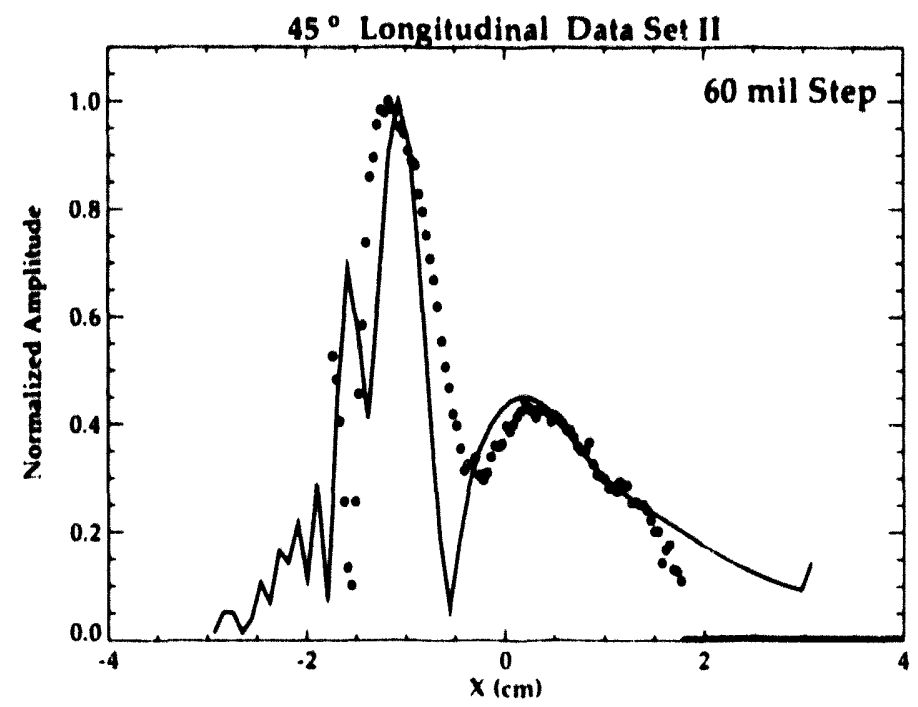

Fig. 6. Comparison of experimental data (Data Set II) for the 60 mil step with theoretical calculations.
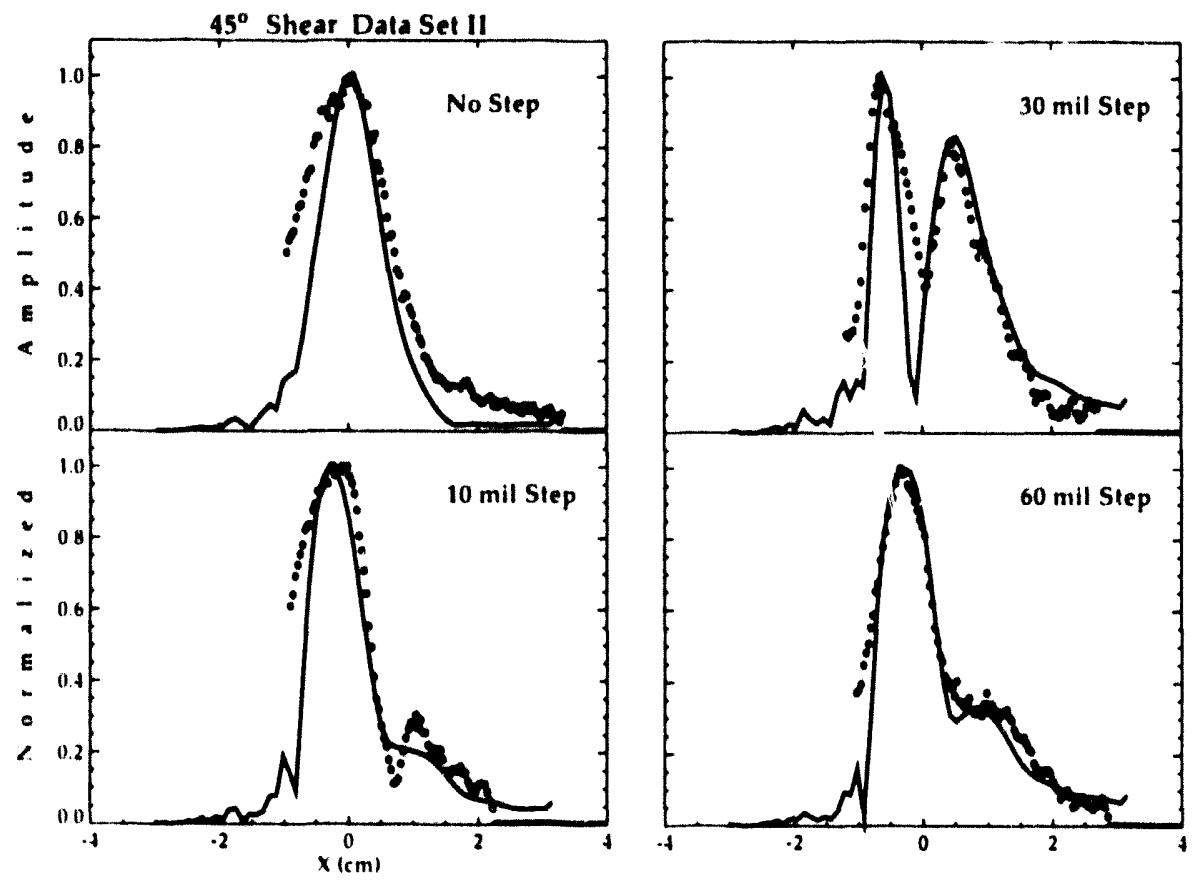

Fig. 7. Comparison of experimental data (Data Set II) with theoretical calculatons for $45^{\circ}$ shear waves.

209

A.7

NUREG/CR-4469, Vol. 16 
of the transducer bracket upon the plate. For example, theoretical calculations show that, if the central ray of the transducer is displaced only $1 \mathrm{~mm}$ from the top of the step, significant changes occur in the theoretical curve. It is important to note that in Fig. 6 the agreement between the data and the theoretical curve is very good.

Figures 5 and 7 show the two sets of data obtained for the $45^{\circ}$ shear case and the corresponding theoretical curves. The agreement between the experimental data and the theoretical calculations is very good, and we shall make some comments about this now as well as comparing the two sets of data. For the nostep case, the agreement between theory and experiment is better in Fig. 5. One notes that the experimental data is broader in Fig. 7. For the 10-mil step, the small peaks to the right of the main peak are more pronounced in Fig. 7 . For the 30-mil step, the theoretical calculations agree very favorably with the experimental data in Fig. 5 and only slightly less so in Fig. 7. The reason for this is that the peak on the left side is not as broad in Fig. 5 as in Fig. 7 and the minimum between the two peaks has a smaller value in Data Set I. For the 60-mil step, the theory agrees very well with the data in Fig. 7 due to the existence of a secondary peak that is absent in Fig. 5. The differences in the two sets of data are probably due to slightly different alignments of the transducer bracket relative to the plate.

In conclusion, this model provides a very good description of the data for the normal orientation, for $45^{\circ}$ longitudinal wave generation, and for $45^{\circ}$ shear wave generation. Thus, the hybrid Gauss-Hermite ray-tracing model is validated for the step discontinuity for the goal of ascertaining the adverse effects of surface conditions.

\section{ACKNOWLEDGEMENTS}

Work supported by the U. S. Nuclear Regulatory Commission under Related Services Contract DE-AC06-76RLO 1830; NRC FIN B2289; L. I Muscara, NRC Program Monitor and by the Electric Power Research Institute, Contract RD2687-01; Dr. M. J. Avioli, Project Manager. sions.

We thank Morris S. Good and Aaron A. Diaz for several helpful discus-

\section{REFERENCES}

1. A. Minachi, R. B. Thompson, M. S. Good, and A. A. Diaz, in Review of progress in Quantitative NDE, Vol. 11A, edited by D. O. Thompson and D. E. Chimenti (Plenum Press, New York, 1991), p. 161.

2. M. S. Good, "Significance of Surface Condition upon Ultrasonic Inspection," internal report, June 1987.

3. M. S. Greenwood, "Appendix A: Modeling of a Step Discontinuity," in Nondestructive Examination (NDE) Reliability of Inservice Inspection of Light Water Reactors, Semi-Annual Report April 1991-September 1991, NUREG/CR-4469, Vol. 14,(1992). 


\section{DISTRIBUTION}

No. of

Copies

\section{OFFSITE}

2 A. J. Hiser, Jr. NRC/RES

Mail Stop NS 217C

M. R. Hum

NRC/NRR

Mail Stop 7 D4

G. Johnson

NRC/RES

Mail Stop 7 D4

J. Muscara

NRC/RES

Mail Stop NS 217C

C. Z. Serpan

NRC/RES

Mail Stop NS 217C

J. Strosnider NRC/NRR

Mail Stop 7 D4

J. P. Durr

NRC/Region I

M. C. Modes

NRC/Region I
A. R. Herdt
NRC/Region II
J. J. Blake
NRC/Region II
J. Jacobson
NRC/Region III

No. of

Copies

\section{FOREIGN}

J. R. Tomlinson NDT Application Centre Nuclear Electric plc Timpson Road Wythenshawe Manchester M23 9LL United Kingdom

\section{ONSITE}

50 Pacific Northwest Laboratory

E. S. Andersen

R. E. Bowey

D. M. Boyd

S. H. Bush

A. A. Diaz

S. R. Doctor (30)

J. R. Friley

B. F. Gore

M. S. Greenwood

R. V. Harris

P. G. Heasler

R. J. Kurtz

F. A. Simonen

J. C. Spanner

T. V. Vo

Publishing Coordination

Technical Report Files (5) 

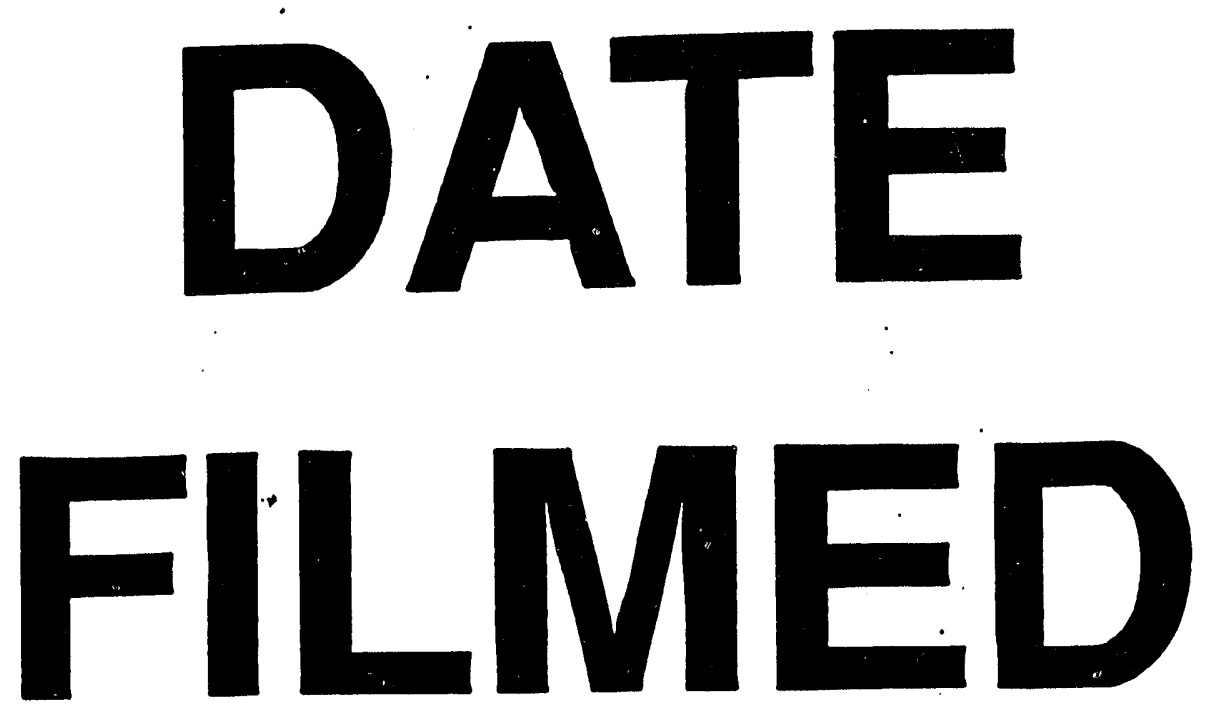

$1 / 12 / 94$
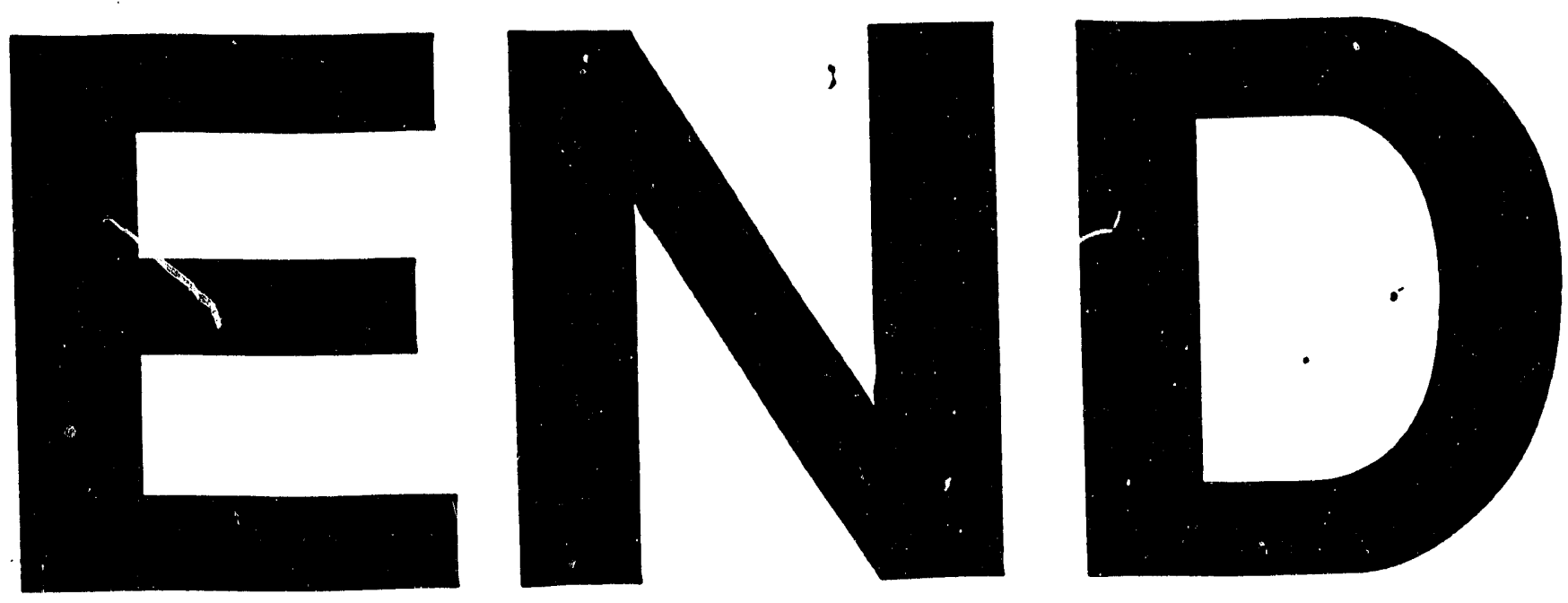


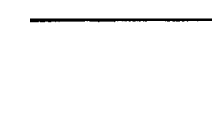

$$
\overline{-}
$$

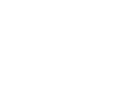

.

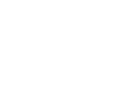

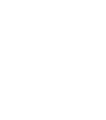

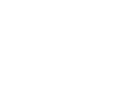

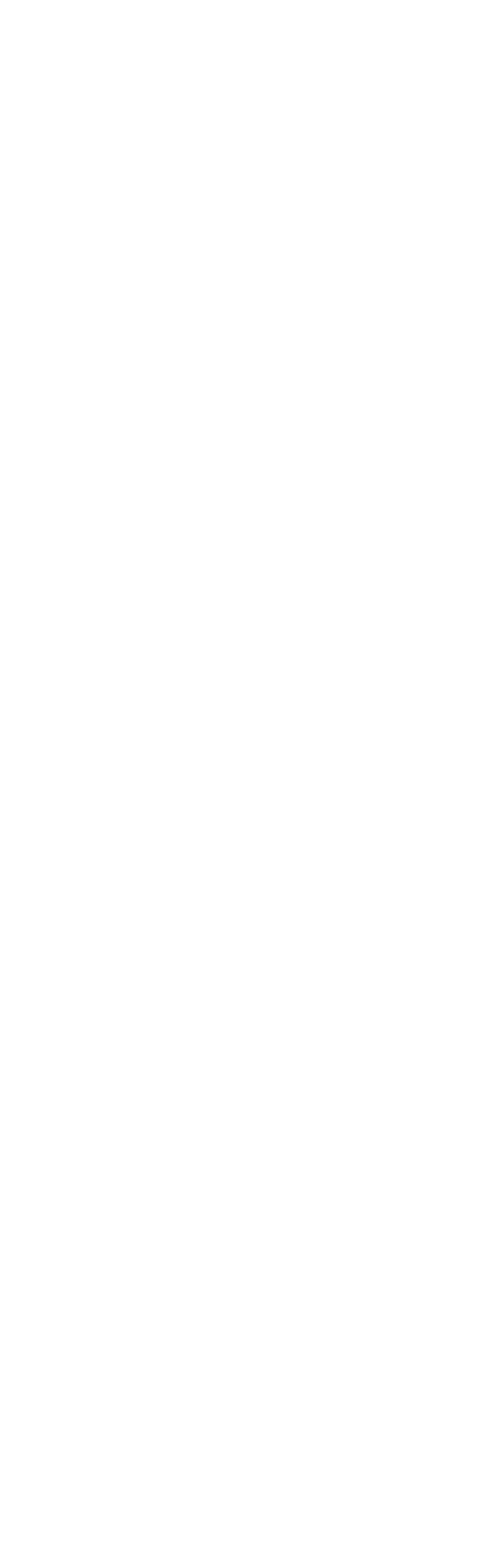

